\title{
Implications of the carbon cycle steady state assumption for biogeochemical modeling performance and inverse parameter retrieval
}

\author{
Nuno Carvalhais, ${ }^{1,2}$ Markus Reichstein, ${ }^{2}$ Júlia Seixas, ${ }^{1}$ G. James Collatz, ${ }^{3}$ \\ João Santos Pereira, ${ }^{4}$ Paul Berbigier, ${ }^{5}$ Arnaud Carrara, ${ }^{6}$ André Granier, ${ }^{7}$ \\ Leonardo Montagnani, ${ }^{8}$ Dario Papale, ${ }^{9}$ Serge Rambal, ${ }^{10}$ María José Sanz, ${ }^{6}$ \\ and Riccardo Valentini ${ }^{9}$ \\ Received 6 June 2007; revised 30 November 2007; accepted 27 December 2007; published 25 April 2008.
}

[1] We analyze the impacts of the steady state assumption on inverse model parameter retrieval from biogeochemical models. An inverse model parameterization study using eddy covariance $\mathrm{CO}_{2}$ flux data was performed with the Carnegie Ames Stanford Approach (CASA) model under conditions of strict and relaxed carbon cycle steady state assumption (CCSSA) in order to evaluate both the robustness of the model's structure for the simulation of net ecosystem carbon fluxes and the assessment of the CCSSA effects on simulations and parameter estimation. Net ecosystem production (NEP) measurements from several eddy covariance sites were compared with NEP estimates from the CASA model driven by local weather station climate inputs as well as by remotely sensed fraction of photosynthetically active radiation absorbed by vegetation and leaf area index. The parameters considered for optimization are directly related to aboveground and belowground modeled responses to temperature and water availability, as well as a parameter $(\eta)$ that relaxed the CCSSA in the model, allowing for site level simulations to be initialized either as net sinks or sources. A robust relationship was observed between NEP observations and predictions for most of the sites through the range of temporal scales considered (daily, weekly, biweekly, and monthly), supporting the conclusion that the model structure is able to capture the main processes explaining NEP variability. Overall, relaxing CCSSA increased model efficiency $(21 \%)$ and decreased normalized average error $(-92 \%)$. Intersite variability was a major source of variance in model performance differences between fixed $\left(\mathrm{CCSSA}_{f}\right)$ and relaxed $\left(\mathrm{CCSSA}_{r}\right)$ CCSSA conditions. These differences were correlated with mean annual NEP observations, where an average increase in modeling efficiency of 0.06 per $100 \mathrm{~g} \mathrm{C} \mathrm{m}^{-2} \mathrm{a}^{-1}$ (where a is years) of NEP is observed $(\alpha<0.003)$. The parameter $\eta$ was found to be a key parameter in the optimization exercise, generating significant model efficiency losses when removed from the initial parameter set and parameter uncertainties were significantly lower under CCSSA $r$. Moreover, modeled soil carbon stocks were generally closer to observations once the steady state assumption was relaxed. Finally, we also show that estimates of individual parameters are affected by the steady state assumption. For example, estimates of radiation-use efficiency were strongly affected by the $\mathrm{CCSSA}_{f}$ indicating compensation effects for the inadequate steady state assumption, leading to

\footnotetext{
${ }^{1}$ Faculdade de Ciências e Tecnologia, Universidade Nova de Lisboa, Caparica, Portugal.

${ }^{2}$ Max-Planck-Institut für Biogeochemie, Jena, Germany.

${ }^{3}$ NASA Goddard Space Flight Center, Greenbelt, Maryland, USA.

${ }^{4}$ Instituto Superior de Agronomia, Tapada da Ajuda, Lisboa, Portugal.

${ }^{5}$ UR1263 Ecologie Fonctionnelle et Physique de L'environnement, Institut National de la Recherche Agronomique, Bordeaux, France.

Copyright 2008 by the American Geophysical Union. 0886-6236/08/2007GB003033
}

\footnotetext{
${ }^{6}$ Fundacion Centro de Estudios Ambientales del Mediterráneo, Valencia, Spain.

${ }^{7}$ Ecologie et Ecophysiologie Forestières, Institut National de la Recherche Agronomique, Centre de Nancy, Champenoux, France.

${ }^{8}$ Servizi Forestali, Agenzia per l'Ambiente, Provincia Autonoma di Bolzano, Bolzano, Italy.

${ }^{9}$ Department of Forest Environment and Resources, University of Tuscia, Viterbo, Italy.

${ }^{10}$ DREAM Unit, Centre d'Ecologie Fonctionelle et Evolutive, CNRS, Montpellier, France.
} 
effective and thus biased parameters. Overall, the importance of model structural evaluation in data assimilation approaches is thus emphasized.

Citation: Carvalhais, N., et al. (2008), Implications of the carbon cycle steady state assumption for biogeochemical modeling performance and inverse parameter retrieval, Global Biogeochem. Cycles, 22, GB2007, doi:10.1029/2007GB003033.

\section{Introduction}

[2] The quantification and the understanding of the main processes controlling biosphere-atmosphere fluxes are central to advancing understanding of terrestrial carbon cycle. The stable implementation of independent monitoring infrastructures, such as the eddy covariance measurements of ecosystem gas exchange networks (e.g., Ameriflux, Euroflux), contributes new information needed for ecosystem modeling of vegetation dynamics and interactions with the atmosphere [e.g., Baldocchi et al., 2000; Falge et al., 2002]. These measurements provide crucial information needed for modeling ecosystem processes and interactions with the atmosphere and upscaling of flux processes for regionalscale carbon balance estimates [Papale and Valentini, 2003; Tenhunen et al., 1998].

[3] In particular model-data synthesis approaches have become popular and have shown large potential for improving and constraining biogeochemical models [e.g., Law et al., 2000; Reichstein et al., 2003; Xu et al., 2006]. In principle all three elements of such a model-data synthesis, the model itself, the data and the parameter estimation algorithm have to be investigated with respect to errors and uncertainties introduced by them. Past research has addressed the effect of observation errors [Rannik et al., 2006; Richardson et al., 2006b] and analyzed the influence of different parameter estimation algorithms [Trudinger et al., 2007], but largely neglected errors introduced by "false" model structure (but see Richardson et al. [2006a]).

[4] One common problematic feature of virtually all process-oriented biogeochemical models is the requirement for initialization which is usually achieved by a spin-up run of the model, i.e., a run of the model to steady state conditions for a specified vegetation type by repeating climate conditions over several hundreds to thousands of years [Law et al., 2001; Pietsch and Hasenauer, 2006]. Previous works challenged the inherent concepts behind carbon cycle steady state assumption (CCSSA) in modeling [e.g., Cannell and Thornley, 2003; Lugo and Brown, 1986]. Nonetheless, CCSSA is commonly assumed in most studies over a considerable range of temporal and spatial scales [Box, 1988; Law et al., 2001; Morales et al., 2005; Potter et al., 1998; Schimel et al., 1997]. Differences in research goals and specific case studies entail different levels of exposure to CCSSA caveats and limitations, such as overestimation of pools or of faster decay rates of recalcitrant pools [Pietsch and Hasenauer, 2006; Wutzler and Reichstein, 2007]. Examples of parameterization studies considering CCSSA include: model intercomparison studies supported by eddy covariance measurements [Amthor et al., 2001]; turnover times of vegetation and soil pools [Barrett, 2002]; and model parameter optimization [Dufrêne et al., 2005], based on results for 20 years spinup runs [Epron et al., 2001].

[5] In this study we hypothesize that the CCSSA in biogeochemical modeling and parameter optimization stud- ies tends to reduce model performance, as well as to bias parameter estimates and respective constraints in modeldata fusion approaches. We suspect that model initialization until equilibrium may lead to compensation effects on optimized parameters when observations show sink or source ecosystem behavior.

[6] In this context we used a model-data synthesis approach, combining observations from multiple sites from the CarboEurope-IP (Integrated Project) Network (http:// www.carboeurope.org/) with a biosphere model. We used the Carnegie Ames Stanford Approach (CASA) model to simulate biosphere-atmosphere carbon fluxes [Field et al., 1995; Friedlingstein et al., 1999; Potter et al., 1993; Randerson et al., 1996] which integrates the general CCSSA principles. The optimization focused on parameters associated with the governing functions driving the main processes behind carbon fluxes variability. Inferences about CCSSA significance in model performance and parameterization are supported by inspection of the optimization results from a defined ensemble of parameter sets.

\section{Materials and Methods}

\subsection{Eddy Covariance Data and Sites}

[7] Under the auspices of the CarboEurope-IP an extensive set of eddy covariance flux measurement towers has been established all over Europe, supporting ecosystem level research on energy and mass transfer processes [Aubinet et al., 2000]. From this network a limited set of sites was chosen for the current study (Table 1). The selection focused mainly on Mediterranean climate classes or ecosystems present in the Iberian Peninsula [Oak Ridge National Laboratory Distributed Active Archive Center (ORNL DAAC), 2006a] that met minimum data availability requirements for remotely sensed variables and in situ measurements of climate variables and ecosystem $\mathrm{C}$ fluxes. The final selection of sites includes deciduous broadleaf (DBF), evergreen needleleaf (ENF), mixed deciduous/evergreen (MF), and evergreen broadleaf (EBF) forests, as well as an evergreen broadleaf scattered tree canopy (savannah type) with understorey (EBG). The site selection NEP ranges between -75.4 and $566.7 \mathrm{gC} \mathrm{m}^{-2} \mathrm{a}^{-1}$ (where a is years), reflecting different ecosystem development stages, as a result of different types and intensities of past and present disturbances. Though this study focuses on a limited number of plant functional types and climate regimes, the site collection characteristics represent a manageable set for testing our hypothesis on the impacts of the steady state assumption on model optimization.

[8] The selected sites have experienced varying disturbance histories, management practices and climate regimes. ES-ES1 last disturbances report to 1986 after which became a natural area: no fire or human disturbances (construction projects) since the 1970s. IT-Non is a reforestation site that transited from agricultural to a forested area in 1992. IT-PT1 
Table 1. Identification of the Different Sites Included in the Parameter Optimization Analysis

\begin{tabular}{|c|c|c|c|c|c|c|c|c|c|}
\hline Site Name & $\begin{array}{l}\text { Site } \\
\text { Code }\end{array}$ & $\begin{array}{c}\text { Plant } \\
\text { Functional Type }^{\mathrm{a}}\end{array}$ & $\begin{array}{c}\text { Latitude } \\
\text { (decimal degrees) }\end{array}$ & $\begin{array}{c}\text { Longitude } \\
\text { (decimal degrees) }\end{array}$ & $\begin{array}{l}\text { Precipitation }{ }^{\mathrm{b}} \\
\quad\left(\mathrm{mm} \mathrm{a}^{-1}\right)\end{array}$ & $\begin{array}{c}\text { Mean } \\
\text { Temperature } \\
\left({ }^{\circ} \mathrm{C}\right)\end{array}$ & $\begin{array}{c}\text { Solar } \\
\text { Radiation } \\
\left(\mathrm{MJ} \mathrm{m}^{-2}\right)\end{array}$ & $\begin{array}{c}\text { Mean } \\
\text { NEP } \\
\left(\mathrm{g} \mathrm{C} \mathrm{m}^{-2} \mathrm{a}^{-1}\right)\end{array}$ & $\begin{array}{c}\text { Observation } \\
\text { Years }\end{array}$ \\
\hline El Saler & ES-ES1 & ENF & 39.34 & -0.32 & 615.32 & 17.45 & 586.16 & 310.59 & $2000-2004$ \\
\hline Hesse & FR-Hes & DBF & 48.67 & 7.06 & 945.41 & 10.94 & 443.46 & 566.69 & $2000-2003$ \\
\hline Le Bray & FR-LBr & ENF & 44.72 & -0.77 & 616.75 & 14.47 & 448.51 & 214.11 & $2000-2002$ \\
\hline Puechabon & FR-Pue & EBF & 43.74 & 3.60 & 974.08 & 13.67 & 513.97 & 192.07 & $2000-2002$ \\
\hline Nonantola & IT-Non & $\mathrm{MF}$ & 44.69 & 11.09 & 968.89 & 13.85 & 537.91 & 478.80 & $2001-2003$ \\
\hline Parco Ticino & IT-PT1 & DBF & 45.20 & 9.07 & 743.41 & 14.89 & 541.54 & 555.20 & $2002-2003$ \\
\hline Renon & IT-Ren & ENF & 46.59 & 11.43 & 1107.41 & 4.86 & 545.51 & 565.93 & $2000-2002$ \\
\hline Roccaresp.1 & IT-Ro1 & DBF & 42.39 & 11.92 & 973.10 & 16.51 & 520.75 & -75.37 & $2002-2002$ \\
\hline Roccaresp.2 & IT-Ro2 & DBF & 42.41 & 11.93 & 772.43 & 14.98 & 536.93 & 543.71 & $2002-2003$ \\
\hline Mitra & PT-Mi1 & EBG & 38.54 & -8.00 & 673.07 & 15.70 & 610.70 & 70.31 & $2002-2004$ \\
\hline
\end{tabular}

${ }^{a}$ The several plant functional types include: evergreen needleleaf forest (ENF); evergreen broadleaf forest (EBF); deciduous broadleaf forest (DBF); mixed forest (MF); evergreen broadleaf with grasses (EBG).

${ }^{\mathrm{b}}$ The presented total annual precipitation, mean annual temperature and net ecosystem carbon fluxes refer to each site's data temporal range used in the current study.

is a managed poplar plantation site with rotation of 912 years, last planted in 1993 and cut in 2005, where the residues and stumps are removed after each logging to allow ploughing, causing significant reductions in soil $\mathrm{C}$ [Ferré et al., 2005]. IT-Ren harvest cycles represent a $10 \%$ removal of aboveground biomass (mean tree age $\approx 85$ years). ITRo1 and IT-Ro2 are two coppice management sites with very different soil $\mathrm{C}$ estimates, caused by differences in times since coppicing: 2 and 11 years, respectively [Rey et al., 2002]. At IT-Ro2, the total precipitation for IT-Ro2 in 2003 was half of 2002 records, suggesting a significant drought in 2003. FR-Hes is a young Beech stand ( $\sim 34$ years old). In FR-LBr, forest management practices include selective thinning (1991 and 1996, 20\% of stems removed) [Loustau et al., 1999]. Two major disturbances were observed at this site: a wind storm in December 1999 (destroying $19.4 \%$ of the stems) and a summer drought in 2002, significantly reducing NEP. The latest disturbances recorded in FR-Pue consist on a clear cut circa 60 years ago [Joffre et al., 1996]. PT-Mil consists of a $Q$. suber and Q. ilex stand ( $\approx 90$ years) strongly influenced by drought regimes [Jarvis et al., 2007; Pereira et al., 2007].

[9] These data sets were processed using a standardized methodology. The fluxes of $\mathrm{CO}_{2}$ were first corrected for within canopy $\mathrm{CO}_{2}$ storage, then controlled for insufficient turbulence ( $\mathrm{u}^{*}$ filtered) and outliers ("spikes"), and partitioned into gross primary productivity and ecosystem respiration [Papale et al., 2006; Reichstein et al., 2005]. Uncertainties of the data processing are discussed and quantified therein. Gap filling was performed according to the marginal distribution sampling method [Reichstein et al., 2005], for which uncertainties were quantified in gap filling by Moffat et al. [2007]. Systematic errors in eddy covariance fluxes due to nonideal observation conditions (e.g., advection and the imbalance in the energy budget) are under intensive research and remain to be further quantified [Aubinet et al., 2005].

[10] Fluxes were aggregated into daily, weekly and monthly integrals by summing up the half-hourly gap-filled flux estimates. Flux integrals were only used for the analysis when more than $80 \%$ of the half-hourly data were either original or gap filled with high confidence (Reichstein et al.'s [2005] Category A; see also http://gaia.agraria.unitus. it/database/eddyproc/). This is a heuristic compromise between avoiding the use of gap-filled data for model parameterization and disregarding valuable data information.

\subsection{Model Description}

[11] The Carnegie-Ames Stanford Approach (CASA) model [Field et al., 1995; Friedlingstein et al., 1999; Potter et al., 1993; Randerson et al., 1996] is a production efficiency model [Ruimy et al., 1999], estimating net ecosystem production (NEP) as the difference between net primary production (NPP) and soil heterotrophic respiration (Rh). Model's NPP estimates are based on the concept of radiation use efficiency [Monteith, 1972, 1977] and calculated as the product between absorbed photosynthetically active radiation (APAR) and light use efficiency $(\varepsilon)$ :

$$
N P P=A P A R \cdot \varepsilon,
$$

where APAR is expressed by the product between fraction of photosynthetically active radiation absorbed by vegetation (FAPAR) and the amount of photosynthetically active radiation (PAR):

$$
\mathrm{APAR}=\mathrm{FAPAR} \times \mathrm{PAR}
$$

and $\varepsilon$ is calculated by down regulating maximum light use efficiency $\left(\varepsilon^{*}\right)$ via the effect of temperature $\left(T_{\varepsilon}\right)$ and water $\left(W_{\varepsilon}\right)$ stress factors:

$$
\varepsilon=\varepsilon^{*} \cdot T_{\varepsilon} \cdot W_{\varepsilon} .
$$

[12] On the other hand, $\mathrm{Rh}$, resulting from microbial mediated decomposition of plant and soil organic residues, can be generically described as:

$$
R h=\sum_{i}^{p} C_{i} \cdot k_{i} \cdot W_{s} \cdot T_{s} \cdot\left(1-M_{\varepsilon}\right)
$$

where (1) $p$ is the number of pools, (2) $C_{i}$ is the carbon content of pool $i$, (3) $k_{i}$ is the maximum decay rate constant 
Table 2. Parameters Used in the Different Model Optimizations

\begin{tabular}{|c|c|c|c|}
\hline Symbol & Parameter Definition & Units & Submodel \\
\hline$\varepsilon^{*}$ & Maximum light use efficiency & $\mathrm{g} \mathrm{C} \mathrm{MJ}^{-1}$ APAR & NPP \\
\hline$T_{\text {opt }}$ & $\begin{array}{l}\text { Optimum temperature } \\
\text { for photosynthesis }\end{array}$ & ${ }^{\circ} \mathrm{C}$ & NPP \\
\hline$T_{a}$ & Temperature sensitivity below $T_{\mathrm{opt}}$ & Unitless & NPP \\
\hline$T_{b}$ & Temperature sensitivity above $T_{\mathrm{opt}}$ & Unitless & NPP \\
\hline$B_{w \varepsilon}$ & Sensitivity to water stress & Unitless & NPP \\
\hline$Q_{10}$ & $\begin{array}{l}\text { Multiplicative increase in soil } \\
\text { biological activity for a } 10^{\circ} \mathrm{C} \\
\text { increase in temperature }\end{array}$ & Unitless & $\mathrm{Rh}$ \\
\hline$T_{\text {ref }}$ & $\begin{array}{l}\text { Reference temperature in } Q_{10} \\
\quad \text { function }\end{array}$ & ${ }^{\circ} \mathrm{C}$ & $\mathrm{Rh}$ \\
\hline$A_{w s}$ & Sensitivity to water storage & Unitless & $\mathrm{Rh}$ \\
\hline$k$ & Soil pools turnover rates & $\delta \mathrm{t}^{-1}$ & $\mathrm{Rh}$ \\
\hline$\eta$ & Steady state relaxing parameter & Unitless & $\mathrm{Rh}$ \\
\hline
\end{tabular}

of pool $i$, (4) $W_{s}$ is the effect of soil moisture content on decomposition, (5) $T_{s}$ is the effect of temperature on decomposition, and (6) $M_{\varepsilon}$ is the carbon assimilation efficiency of microbes. The carbon content of each pool results from the integrated carbon transfers between litter, microbial and soil pools. In plant pools carbon is gained through NPP and lost because of foliage, wood and root mortality and transferred to microbial and soil organic pools. The CASA model has been widely used in studies ranging from ecosystem to global scales [e.g., Potter et al., 2001; Randerson et al., 2002, 1996]; focusing on different ecological and biogeochemical processes [e.g., Potter et al., 2001, 1998; Randerson et al., 2005]; evaluating disturbances impacts [e.g., Masek and Collatz, 2006; van der Werf et al., 2003]; and integrated with ocean models for global productivity studies [e.g., Behrenfeld et al., 2001; Field et al., 1998].

[13] The CASA model is only a partial mechanistic representation of the main processes governing carbon fluxes between the ecosystem and atmosphere. The level of complexity represents the trade off between biogeochemical detail and tractability for global-scale studies integrating extensive satellite observations and meteorological drivers. The parameterizations of temperature and water stress scalars in CASA aim to reproduce mechanistic effects of both factors on productivity and heterotrophic respiration [Field et al., 1995]. Carbon cycling processes are based on the mechanistic compartment structure of the CENTURY model [Parton et al., 1987] with multiple pools, each with its own turnover time, and is expected to reproduce plausible dynamics allowing examination of the steady state assumption on NEP estimates. Accordingly, CASA is considered suitable to evaluate the steady state impacts on model performance and parameter optimization in inverse biogeochemical modeling and data fusion exercises.

[14] The CASA model inputs include climatologic drivers (mean daily, weekly, biweekly and monthly temperature, total precipitation and solar radiation), vegetation state (plant functional type and fractional tree cover) and biophysical properties (FAPAR and leaf area index), as well as soil properties (texture and rooting depth).

\subsection{Remote Sensing Data}

[15] In the initial CASA model implementation, seasonal vegetation biophysical properties, FAPAR and leaf area index (LAI), were estimated through satellite remotely sensed normalized difference vegetation index (NDVI) estimates [Potter et al., 1993]. The emergence of robust methods for FAPAR and LAI estimations on the basis of radiative transfer principles [Gobron et al., 1997; Knyazikhin et al., 1998; Myneni et al., 1995] are providing remote sensing products of significant usefulness in biophysical modeling. The current study makes use of 8 day composites of FAPAR and LAI products from the Moderate Resolution Imaging Spectroradiometer (MODIS), on board the Terra platform [Myneni et al., 2002], available from ORNL DAAC [2006b]. The identification of poor quality records flagged by ancillary data sets and the occurrence of not flagged sudden underestimation spikes (mainly associated to atmospheric contamination) lead to the FAPAR and LAI time series treatment based on two different methods: (1) the best index slope extraction (BISE) [Viovy et al., 1992] and (2) a Fourier Wave Adjustment (FWA) [Sellers et al., 1996]; both supported by robust relationships with other variables and/ or information contained from good quality neighboring pixels (Text S2 and Figure S3). ${ }^{1}$ The rationale behind this approach is the minimization of poor model performance in the optimization procedure resulting from low data quality issues in input data.

\subsection{Optimized Parameters Description}

[16] The first step in selecting parameter sets for optimization was the identification of scalars governing both NPP and $\mathrm{Rh}$ processes. Chosen parameters are mainly related to temperature and water response curves, although maximum energy mass conversion rates (light use efficiency) and soil carbon turn over rates were also evaluated (Table 2). Furthermore, a parameter $(\eta)$ was defined that scaled soil carbon pools (microbial and slow turnover rate's pools) at the end of the initialization process, allowing for the impact assessment of the CCSSA in the model performance and parameter constraints. In this context, the simulation of carbon source or sink ecosystems becomes possible by relaxing the CCSSA approach at the end of the model spin up, reducing the possibility of compensating effects biasing other model parameters (Text S1 and Figures S1 and S2).

[17] The selection of the main set of parameters for optimization focused on the temperature and water stress response scalars affecting both NPP $\left(T_{\text {opt }}\right.$ and $\left.B_{w e}\right)$ and Rh $\left(Q_{10}\right.$ and $\left.A_{w s}\right)$, the two principal environmental controls on NEP, as well as energy-mass conversion rates $\left(\varepsilon^{*}\right)$ and the CCSSA relaxing parameter $(\eta)$ (Table $3 ; S_{0}$ ). In order to assess the significance of $\eta$ in the initial parameter set $\left(S_{0}\right)$ six new parameter sets were created by removing each element of $S_{0}$ individually, generating the parameter vectors $S_{\varepsilon^{*}}^{-}, S_{T o p t}^{-}, S_{B w \varepsilon}^{-}, S_{Q 10}^{-}, S_{A w s}^{-}$, and $S_{\eta}^{-}$(the minus superscript indicates the removal of the parameter in the subscript). The initial value (a standard value that was also the initial guess when included in the optimization) was used for each parameter removed from the optimization (Text S1). Four other parameters related to temperature control on carbon assimilation $\left(T_{a}\right.$ and $\left.T_{b}\right)$ and respiration $\left(T_{\text {ref }}\right)$ processes, as

\footnotetext{
${ }^{1}$ Auxiliary materials are available in the HTML. doi:10.1029 2007GB003033.
} 
Table 3. Identification of the Different Parameters Included in Each Parameter Set

\begin{tabular}{ccccccccccc}
\hline & \multicolumn{110}{c}{ Parameter } \\
\cline { 2 - 10 } Parameter Set $^{\mathrm{a}}$ & $\varepsilon^{*}$ & $T_{\mathrm{opt}}$ & $B_{w \varepsilon}$ & $Q_{10}$ & $A_{w s}$ & $\eta$ & $k$ & $T_{a}$ & $T_{b}$ & $T_{\text {ref }}$ \\
\hline$S_{0}$ & $\mathrm{X}$ & $\mathrm{X}$ & $\mathrm{X}$ & $\mathrm{X}$ & $\mathrm{X}$ & $\mathrm{X}$ & & & & \\
$S_{k}^{+}$ & $\mathrm{X}$ & $\mathrm{X}$ & $\mathrm{X}$ & $\mathrm{X}$ & $\mathrm{X}$ & & $\mathrm{X}$ & & & \\
$S_{T a}^{+}$ & $\mathrm{X}$ & $\mathrm{X}$ & $\mathrm{X}$ & $\mathrm{X}$ & $\mathrm{X}$ & & & $\mathrm{X}$ & & \\
$S_{T b}^{+}$ & $\mathrm{X}$ & $\mathrm{X}$ & $\mathrm{X}$ & $\mathrm{X}$ & $\mathrm{X}$ & & & & $\mathrm{X}$ & \\
$S_{T \text { ref }}^{+}$ & $\mathrm{X}$ & $\mathrm{X}$ & $\mathrm{X}$ & $\mathrm{X}$ & $\mathrm{X}$ & & & & & $\mathrm{X}$ \\
$S_{\varepsilon^{*}}^{+}$ & & $\mathrm{X}$ & $\mathrm{X}$ & $\mathrm{X}$ & $\mathrm{X}$ & $\mathrm{X}$ & & & & \\
$S_{T \mathrm{opt}}^{-}$ & $\mathrm{X}$ & & $\mathrm{X}$ & $\mathrm{X}$ & $\mathrm{X}$ & $\mathrm{X}$ & & & & \\
$S_{B w \varepsilon}^{-}$ & $\mathrm{X}$ & $\mathrm{X}$ & & $\mathrm{X}$ & $\mathrm{X}$ & $\mathrm{X}$ & & & & \\
$S_{Q 10}^{-}$ & $\mathrm{X}$ & $\mathrm{X}$ & $\mathrm{X}$ & & $\mathrm{X}$ & $\mathrm{X}$ & & & & \\
$S_{A w s}^{-}$ & $\mathrm{X}$ & $\mathrm{X}$ & $\mathrm{X}$ & $\mathrm{X}$ & & $\mathrm{X}$ & & & & \\
$S_{\eta}^{-}$ & $\mathrm{X}$ & $\mathrm{X}$ & $\mathrm{X}$ & $\mathrm{X}$ & $\mathrm{X}$ & & & & & \\
\hline
\end{tabular}

${ }^{a}$ Each capital letter $S$ stands for a parameter set; $S_{0}$ identifies the base parameter set. Whenever $\eta$ is being replaced by any other parameter, the superscript of $S$ will show a plus sign and the subscript will represent the parameter acronym used instead of $\eta$; whenever one parameter present in $S_{0}$ is removed, the superscript will be a minus sign and the subscript will represent the parameter acronym removed from $S_{0}$.

well as the maximum turnover rates of soil carbon pools $(k)$, were examined with regard to their ability to improve model performance for fixed CCSSA. In these cases $\eta$ was removed from the parameter vector and replaced by each of the potential alternatives, yielding four new parameter sets: $S_{k}^{+}, S_{T a}^{+}, S_{T b}^{+}$, and $S_{\text {Tref }}^{+}$(the plus superscript indicates the replacement of $\eta$ by the parameter in the subscript). The complete ensemble of parameter sets can be divided in two different groups: (1) one considering a relaxed CCSSA $\left(\mathrm{CCSSA}_{r}\right)$ composed by all parameter vectors that include $\eta\left(S_{0}, S_{\varepsilon^{*}}^{-}, S_{T o p t}^{-}, S_{B w \varepsilon}^{-}, S_{Q 10}^{-}\right.$, and $\left.S_{A w s}^{-}\right)$and (2) another considering a fixed CCSSA ( $\left.\mathrm{CCSSA}_{f}\right)$ comprising all parameter vectors that exclude $\eta\left(S_{\eta}^{-}, S_{k}^{+}, S_{T a}^{+}, S_{T b}^{+}\right.$, and $\left.S_{\text {Tref }}^{+}\right)$.

\subsection{Parameter Optimization Method}

[18] Eddy covariance measurements of $\mathrm{CO}_{2}$ fluxes and simulated NEP estimates were used to estimate the model parameters independently for each parameter set and for each site at different temporal scales. The optimization method consisted of the minimization of a cost function (least sum of residual squares) by the Levenberg-Marquardt algorithm [Draper and Smith, 1981]. Standard errors and covariances of parameter estimates were calculated as the square root of the diagonal elements of the parameter covariance matrix that in turn was calculated from the Jacobi matrix and the sum of residual squares according to Draper and Smith [1981], using standard assumptions (e.g., normality and independence of the residuals). For half-hourly fluxes Richardson et al. [2006b] found random errors to be non-Gaussian distributed, but this result is currently under debate since it could partly emerge from superposition of several Gaussian distributions with varying variance, e.g., when pooling nighttime and daytime data [Lasslop et al., 2008]. For longer-time integrals flux errors tend to become more Gaussian [Richardson et al., 2008] which is consistent with the central limit theorem. An exact characterization at daily to monthly timescales remains to be done, but is out of scope and focus of the current study and would not likely change the major conclusions derived here.
[19] The parameter optimization was performed individually by site, parameter set, temporal resolution and remote sensing correction, providing independent results in a full factorial design. We followed a strategy similar to Wang et al. [2006], where each optimized parameter is normalized by its initial value, that is $\delta=P / P_{0}$, being $P$ the optimized parameter and $P_{0}$ the initial parameter value. Consequently, the optimization lies on $\delta$, rather than on $P$, where $P$ was calculated as $P=\delta^{T} P_{0}$, since all $P_{0}$ are set the same for all simulations.

\subsection{Statistical Analysis}

[20] The CASA model performance is evaluated through different statistical indices by comparing NEP simulations against measurements, for the different sites according to Janssen and Heuberger [1995]. Four main indices were chosen to evaluate the model performance in different perspectives: (1) the Normalized Average Error (NAE), expressing mean model biases when compared to observations; (2) the Variance Ratio (VR), aiming to analyze the pattern of variability generated by simulations through the ratio between estimates' and observations' variance; (3) the modeling efficiency (MEF), measuring the variance of the predictions from the one-to-one prediction line [Nash and Sutcliffe, 1970] and sensitive to systematic deviations between model and observation [Smith et al., 1996]; as well as the commonly used (4) coefficient of determination or correlation coefficient $\left(r^{2}\right)$ (Text S3).

[21] As a consequence of the current experimental design, the variance observed either in optimized parameters or in model performance measures may be driven by different factors (site, parameter set or temporal resolution) independently or as a result of interactions between them. In order to identify the main determinants of variance of a given variable an n-way analysis of variance (ANOVA) was performed for the three main factors considered, for a 0.05 significance level [Hogg and Ledolter, 1987].

[22] The evaluation of statistical differences between two distributions relied on one-sided Kolmogorov-Smirnov (KS) difference tests [Janssen and Heuberger, 1995] for both higher $(F 1(x)>F 2(x))$ and lower $(F 1(x)<F 2(x))$ alternative hypothesis. The KS tests supported the evaluation of model performance differences between different parameter sets, as well as the identification of differences between optimized parameters and parameters standard errors distributions, at a significance level of 0.05 , throughout sites and temporal scales.

\section{Results and Discussion}

\subsection{General Model Performance}

[23] Generally, model performance results supports significant confidence in model structure, for which robust relationships were observed between simulations and observations throughout the different sites, temporal scales and parameter sets considered (Table 4). These results are further supported by an analysis of variance of model evaluation parameters with site, parameter sets and temporal scale. The main determinants of $r^{2}$ were found to be the sites and the interaction between site and parameter set, 

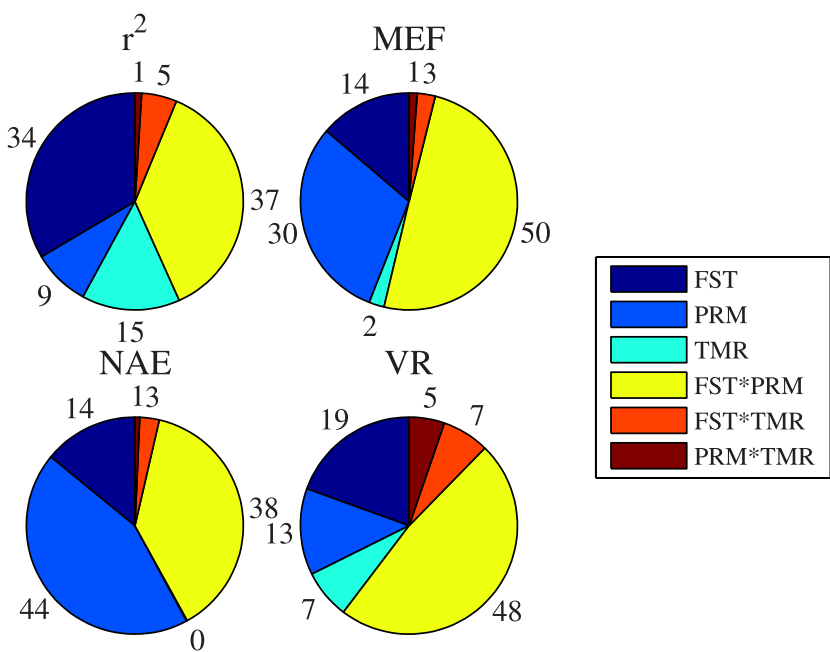

Figure 1. ANOVA test results on the four model performance indicators yielded by the CASA model optimization throughout sites (FST) and temporal resolutions (TMR) for all parameter sets considered (PRM). The percentage values correspond to the variance explained by each factor or combination of factors over the total explained variance. Here $r^{2}$ is correlation coefficient, MEF is modeling efficiency, NAE is normalized average error, and VR is variance ratio.

respectively responsible for 34 and $37 \%$ of the explained variability in $r^{2}$ (Figure 1). Variance ratios $<1$ indicate a systematic underestimated variance in simulations, reflecting model structure deficiencies in modeling processes responsible for extreme (positive and negative) NEP observations, but also reflect noise in the observed eddy flux data themselves that is not reproduced by the model [Moffat et al., 2007], which ultimately limit the agreement between models and observations. The main isolated determinant of MEF and NAE variance was found to be parameter set responsible for 30 and $44 \%$ of its variability, respectively, while the interaction between site and parameter set explain 50 and $38 \%$ of MEF and NAE variance, respectively. MEF values yield satisfactory model performance [Quinton, 1997], indicating model's suitability for simulating carbon fluxes at the different temporal scales (Figure 2). NAE results show a positive bias, underestimating NEP for sink situations, and vice versa, indicating that in an average sense the model has a tendency to approach null balances (Table 4).

[24] The ANOVA results for the main determinants of model performance generally show significant variability from site to site and with parameter selection. The main effects of parameter set are observed in NAE and in MEF, showing the parameter set selection relevance in reducing model's residuals. Overall, model performance measures (Table 4) demonstrate the model's ability in simulating net ecosystem fluxes.

\subsection{Parameter Set Selection}

[25] The current experimental design generated one correlation matrix per optimization run, yielding multiple results per parameter comparison pair, varying with site, temporal resolution and parameter set. Correlation matrix results showed negligible to low covarying pairs of parameters in most cases $(70 \%)$, although moderate $(15 \%)$ marked $(10 \%)$ and high $(5 \%)$ correlations were also observed. Significant reductions in correlation between parameters are observed when increasing temporal resolution (Table $\mathrm{S} 1$ ). Thus it seems that there is information in the daily data, that allows to better resolve individual processes represented by model parameters and that help to reduce parameter correlations that occur when the day-to-day variability is smoothed to weekly or monthly time steps.

\subsection{CCSSA Impacts on Model Performance}

[26] Model performance results for $S_{0}$ optimization showed lower model biases, indicating that $\operatorname{CCSSA}_{r}$ brought modeled NEP closer to observations (closer to the one-to-one line; Figure 3). MEF and NAE results show improvement trends from $S_{\eta}^{-}$to $S_{0}$ of 0.21 and -0.92 , on average, respectively. A strong relationship was found between mean annual NEP observations and MEF increases for $\mathrm{CCSSA}_{r}$, where an average increase in MEF of 0.06 is observed per $100 \mathrm{~g} \mathrm{C} \mathrm{m}^{-2} \mathrm{a}^{-1}$ of NEP $(\alpha<0.003)$. These results indicate that the integration of $\eta$ in the parameter set for optimization generates improvements in effective net fluxes estimates (Figure 4b), suggesting improved estimates

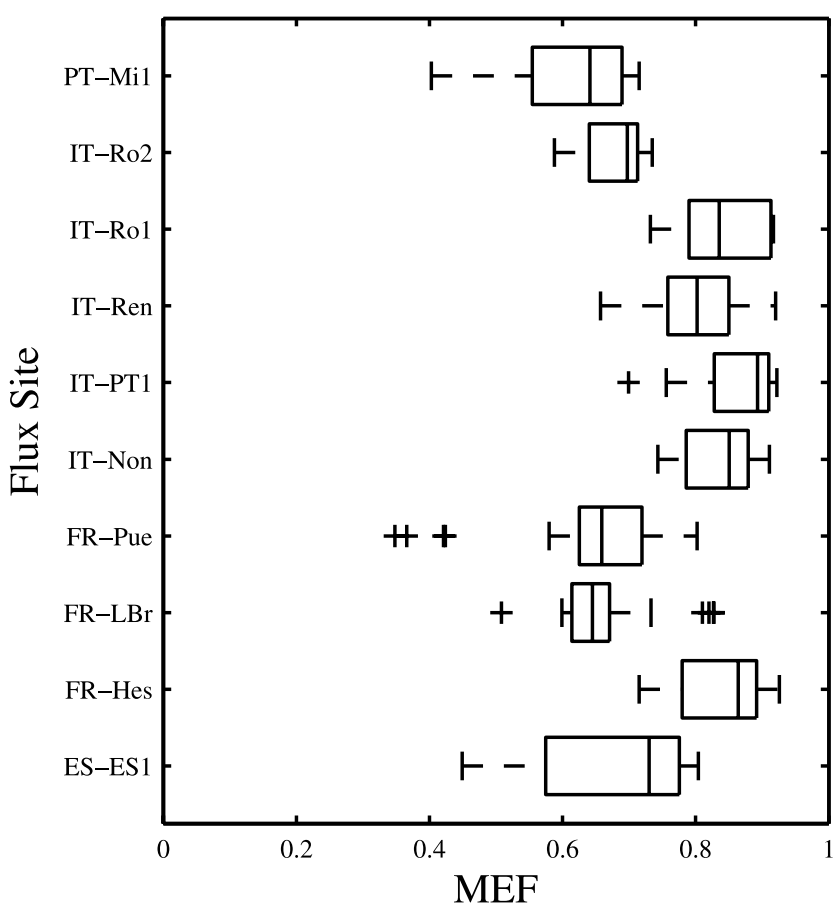

Figure 2. MEF distribution for simulations where $\eta$ is considered in the parameter set $\left(\mathrm{CCSSA}_{r}\right)$. Rectangular boxes are bounded by 25th (right) and 75th (left) percentile, while the vertical line inside indicates the sample median; dashed lines limited by vertical bars indicate the extent of the remaining data, excluding outliers; plus signs indicate statistical outliers. 
Table 4. Model Performance Results for Different Temporal Resolutions (Mean \pm Standard Deviation)

\begin{tabular}{lcccc}
\hline & \multicolumn{4}{c}{ Temporal Resolution } \\
\cline { 2 - 5 } Statistics & Daily & Weekly & Biweekly & Monthly \\
\hline$r^{2}$ & $0.66 \pm 0.14$ & $0.75 \pm 0.13$ & $0.77 \pm 0.14$ & $0.74 \pm 0.14$ \\
MEF & $0.57 \pm 0.23$ & $0.65 \pm 0.27$ & $0.66 \pm 0.29$ & $0.66 \pm 0.27$ \\
NAE & $0.49 \pm 0.62$ & $0.54 \pm 0.89$ & $0.50 \pm 0.63$ & $0.47 \pm 080$ \\
VR & $0.66 \pm 0.18$ & $0.76 \pm 0.16$ & $0.75 \pm 0.19$ & $0.74 \pm 0.18$ \\
\hline
\end{tabular}

of the other parameters and thus a better representation of environmental variability effects on NEP. By relaxing the common steady state assumption and hence allowing flexibility to soil carbon pool sizes, $\eta$ allows for regulation of carbon efflux from the soil as a function of distance to an equilibrium stage, permitting higher process sensitivity to environmental conditions. The only systematic exception to the previously referred improvements by including $\eta$ in the parameter set for optimization was PT-Mi1, which is a weak carbon sink, generally yielding $\eta$ values close to unity.

[27] We further tested if the improving effect of $\eta$ could also have been achieved instead by optimizing other parameters. Replacing $\eta$ with optimized soil pools maximum turn over rates $\left(S_{k}^{+}\right)$or temperature effects on NPP $\left(S_{T a}^{+}\right.$and $\left.S_{T b}^{+}\right)$ or $\mathrm{Rh}\left(S_{\text {Tref }}^{+}\right)$produced poorer agreement with observations than $S_{0}$ optimizations. Both MEF and NAE statistics showed reductions throughout sites and temporal scales compared to simulations where $\eta$ was included to relax the steady state assumption (Figure 5). The differences between $S_{0}$ versus $\operatorname{CCSSA}_{f}\left(S_{k}^{+}, S_{T a}^{+}, S_{T b}^{+}\right.$and $\left.S_{T \text { ref }}^{+}\right)$, evaluated independently per parameter set, show a mean increase of 0.20-0.36 in MEF and a mean decrease of 0.85-0.96 in NAE under $\mathrm{CCSSA}_{r}$ conditions. MEF differences reveal a significant relationship $(\alpha<0.001)$ with mean annual NEP values throughout temporal scales, showing an average increase in MEF of 0.04 per $100 \mathrm{~g} \mathrm{C} \mathrm{m}^{-2} \mathrm{a}^{-1}$ of NEP, which is consistent with the previous relationship found for $S_{0}$ versus $S_{\eta}^{-}$. These results indicate that neither environment response curve related parameters $\left(S_{T a}^{+}, S_{T b}^{+}\right.$, and $\left.S_{T r e f}^{+}\right)$, nor carbon mineralization rates of soil pools $\left(S_{k}^{+}\right)$(Figure $4 \mathrm{a}$ ) can substitute the effect of $\eta$ on model performance.

[28] In addition to $\eta$, we found $\varepsilon^{*}$ and $T_{\mathrm{opt}}$ to be of significant importance in $S_{0}$, since the removal of each individually yielded significant differences in model performance (Figure 5; $S_{\varepsilon^{*}}^{-}$and $S_{\text {Topt }}^{-}$). The exclusion of $\varepsilon^{*}$ from the optimization $\left(S_{\varepsilon^{*}}^{-}\right)$limits the ranges of NPP seasonality in the simulations by imposing a fixed $\varepsilon^{*}$, causing significant increases in VR (not shown) and decreases in MEF (Figure 5). Optimizing NEP fluxes with such an imposed limited NPP seasonality also reduces the model's capacity in correctly simulating higher NEP fluxes (Figure 4c). Further, we found that by replacing $T_{\text {opt }}$ from the initial parameter set $\left(S_{\text {Topt }}^{-}\right)$with a prescribed value (in this case $25^{\circ} \mathrm{C}$ ), we reduced agreement between modeled and observed seasonal cycle in NPP expressed as significant reductions in $r^{2}$ (not shown) and MEF (Figure 5).

[29] As shown above, simulations' MEF and NAE significantly improved when $\eta$ was included in the optimized parameter vector. Furthermore, a significant correlation was found between MEF and distance to steady state under
$\mathrm{CCSSA}_{r}(\alpha<0.001)$. Moreover, the sites' mean annual NEP values were inversely related to $\eta$ estimates (Figure 6) indicating increasing importance of $\eta$ for ecosystems that are farther from steady state conditions. These results reflect the fact that the introduction of a parameter that scales soil $\mathrm{C}$ pools after spin up is directly related to the magnitude of the source/sink conditions observed at the ecosystem level, through the regulation of substrate availability for Rh. Further, statistically significant performance improvements in both NAE and MEF (Figure 5) and $r^{2}$ support the hypothesis that the underlying mechanisms driving net ecosystem fluxes are better represented by the $\mathrm{CCSSA}_{r}$ optimizations.

[30] In addition to the influence of $\eta$, the significance of both $\varepsilon^{*}$ and $T_{\text {opt }}$ is indicated by the reduction in the quality of model results in $S_{\varepsilon^{*}}^{-}$and $S_{\text {Topt }}^{-}$when compared to $S_{0}$, reflecting that amplitude and seasonality mismatches between observations and simulations occurred as a result of deficiencies in NPP simulations.

\subsection{Factors Controlling Parameters and Their Constraints}

[31] Generally, the main determinants of parameters variability are related to the site, either isolated or through interactions with other factor (Figure S4). The site factor is the main isolated determinant for parameter variability in $\varepsilon^{*}, T_{\mathrm{opt}}$ and $B_{w \varepsilon}(40,39$, and $17 \%$, respectively), followed by parameter set $\left(16,7\right.$, and $9 \%$, respectively). Note that $\varepsilon^{*}$ variability strongly depends on these two factors, site and parameter set, which isolated or interacting account for $89 \%$ of its variability. These results reflect the importance of ecosystem characteristics/properties for $\varepsilon^{*}$, as well as a high sensitivity of parameter selection for its optimization. The main isolated determinants of $Q_{10}$ variability were found to be parameter set $(28 \%)$ and flux site $(9 \%)$, while the interaction behind these two factors determines $56 \%$ of $Q_{10}$ variability. The variability in $A_{w s}$ explained by isolated factors is significantly low $(<15 \%)$, while interaction effects explain more than $85 \%$ if it variability, mainly flux site and parameter set $(55 \%)$. These results suggest parameter set selection is a significant determinant of parameters variance, except for $\eta$ where site alone explains $83 \%$ of its variability.

\subsubsection{Effect of Steady State Assumption on Parameter Estimates}

[32] Under relaxed steady station conditions significant positive correlations were observed between observed mean annual NEP fluxes $(\overline{\mathrm{NEP}})$ and optimized $\varepsilon^{*}$ values, while for strict steady state conditions this correlation was not significant. For daily calculations, the inclusion of $\eta$ in the optimized parameter set $\left(S_{0}\right)$ yielded significant differences in $\varepsilon^{*}$ estimates, positively correlated $(\alpha<0.02)$ to $\overline{\mathrm{NEP}}$ (Figure $7 b$ ). Consequently, differences in $\varepsilon^{*}$ under relaxed and strict steady state conditions were inversely related to $\eta$ values $(\alpha<0.08)$ (Figure 7a), making the latter inversely related to $\overline{\mathrm{NEP}}$ (Figure 6). These results suggest that for $S_{0}$ the sink magnitudes were achieved not only by reducing soil $\mathrm{C}$ pools and hence $\mathrm{Rh}$, through $\eta$ (reducing the soil $\mathrm{C}$ pools, hence $\mathrm{Rh}$ ) but also by increasing $\varepsilon^{*}$ (increasing NPP), consequently increasing NEP estimates. Values found for $\varepsilon^{*}$ (Table 5) showed significant differences with plant functional type (PFT), and usually fell within conversion 

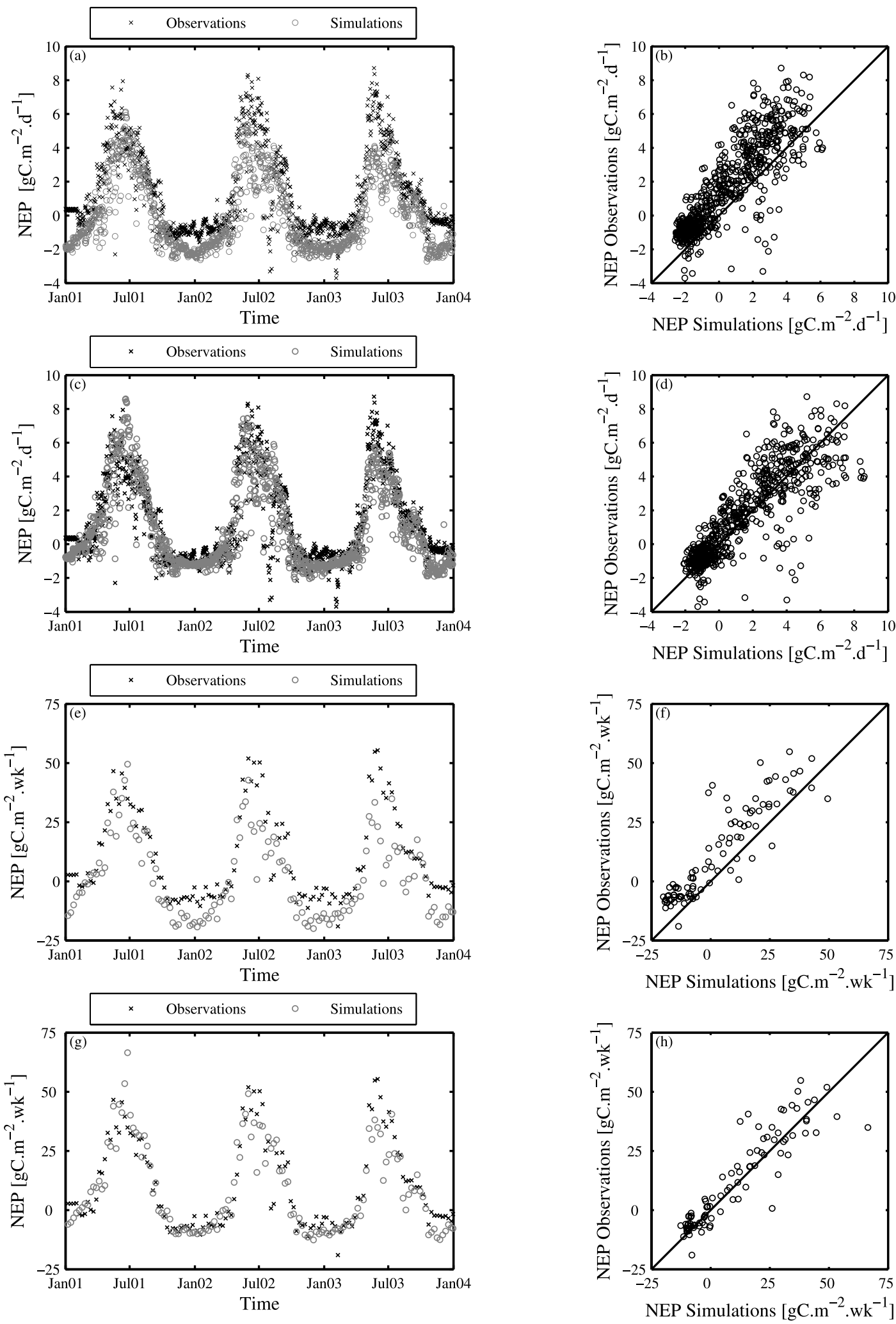

Figure 3. CASA model NEP estimates for IT-Non at different temporal scales: $(\mathrm{a}-\mathrm{d})$ daily calculations and $(\mathrm{e}-\mathrm{h})$ weekly calculations; and CASA model NEP estimates for IT-Non for different parameter sets: (Figures 3a, 3b, 3e, and 3f) under $\operatorname{CCSSA}_{f}\left(S_{\eta}^{-}\right)$and (Figures 3c, 3d, 3g, and 3h) under $\operatorname{CCSSA}_{r}\left(S_{0}\right)$. $\mathrm{CCSSA}_{r}$ reflect an effective improvement by approximating NEP estimates to the one-to-one line. The differences between daily and weekly results illustrate the potential to overlook these effects with noisy data. 


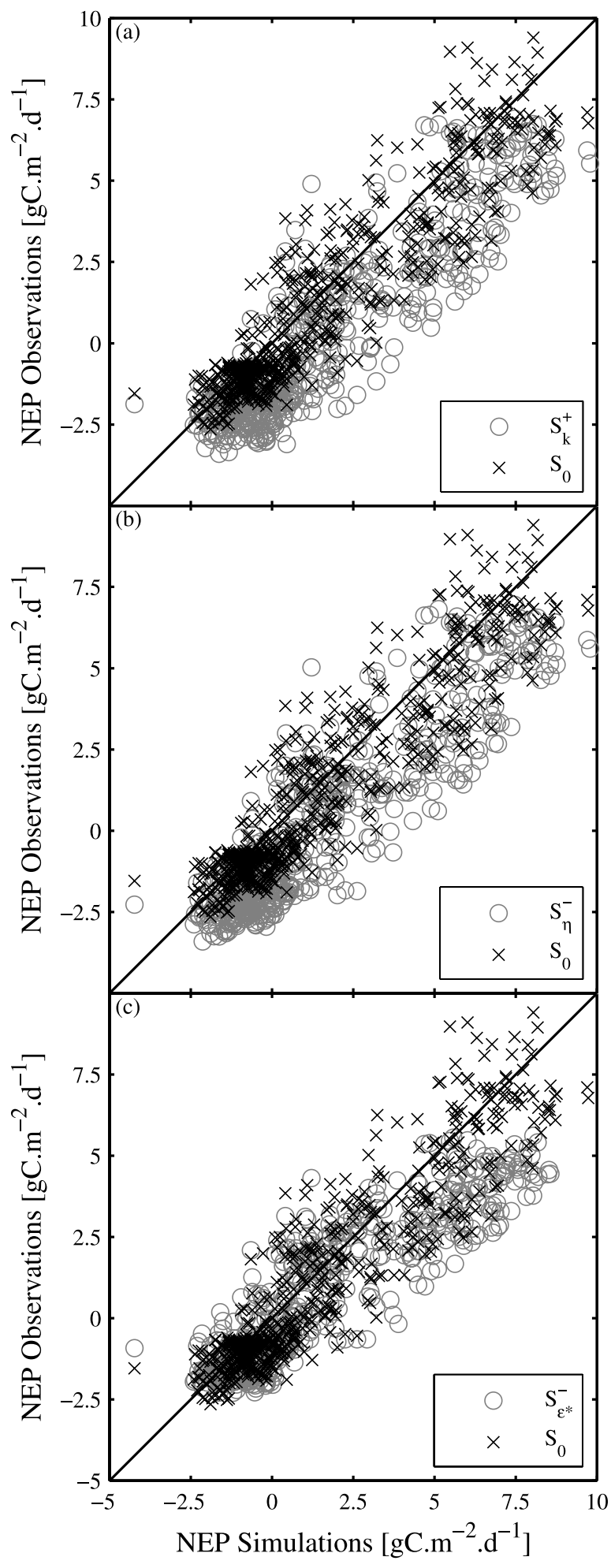

Figure 4. Observations versus simulations results between different parameter sets and $S_{0}$ (IT-PT1). (a and b) Simulations without $\eta\left(S_{\eta}^{-}\right)$or integrating turnover rates instead of $\eta\left(S_{k}^{+}\right)$in the optimization parameter set show higher mismatch with observations. (c) The removal of $\varepsilon^{*}$ $\left(S_{\varepsilon^{*}}^{-}\right)$from the initial parameter set $\left(S_{0}\right)$ significantly affects the agreement between measured and modeled ecosystem fluxes. efficiencies previously compiled by Ruimy et al. [1994], although reported maximums (for cultivated vegetation) per PFT were usually not found in the optimization.

[33] Generally, $T_{\mathrm{opt}}$ estimates fell within those reported by Adams et al. [2004], although no significant differences were found between $T_{\text {opt }}$ estimates under relaxed or fixed steady state conditions (Figure 8a). These results suggest optimized $T_{\mathrm{opt}}$ depends more on day-to-seasonal NEP variability than on annual NEP (sink strength).

[34] Comparing $B_{w e}$ estimates between relaxed $\left(\mathrm{CCSSA}_{r}\right)$ against fixed $\left(\mathrm{CCSSA}_{f}\right)$ steady state simulations we observed significant differences: $\mathrm{CCSSA}_{r}$ estimates were lower than CCSSA $_{f}$ (Figure 8a). Higher $B_{w e}$ values indicate lower sensitivity of light use efficiency to the ratio of estimated evapotranspiration to potential evapotranspiration (PET), hence decreased impact of water deficits on NPP, enabling higher NEP estimates for sites that are carbon sinks. Occasionally, the optimization resulted in unrealistic parameter estimates of $B_{w e}\left(B_{w e}>1\right)$. Although $\mathrm{CCSSA}_{r}$ optimizations show lower occurrence of erratic $B_{w e}$ values, two main reasons were found for such results. One case for spurious $B_{w e}$ optimizations occurred for IT-Ren, where not only estimates of $B_{w e}$ were often higher than one, but also $B_{w e}$ standard errors (SE) ranged 1 order of magnitude higher than for any other sites. The differences in model efficiency between both optimizations were negligible (between 1 and $5.5 \%$ ), as well as differences between the optimization of other parameters (between 0 and 7\%). The optimization insensitivity to $B_{w e}$ in IT-Ren lead to the assumption that here vegetation does not experience water stress. Further analysis on the reasons behind unrealistic $B_{\text {we }}$ retrievals revealed estimated evapotranspiration (EET) showed statistically significant correlations between CASA model EET estimates and EET observations. However, a weak relationship observed between NEP measurements and the observed evapotranspiration-PET ratio (not shown) indicates the data inability to properly constrain $B_{w e}$ in some cases. In such cases of unconstrained parameters Bayesian approaches, where a priori parameter likelihoods are defined, are appropriate, but this is out of the focus of this study.

[35] Throughout parameter sets, $Q_{10}$ estimates ranged within values found in literature [Kätterer et al., 1998; Kirschbaum, 1995; Raich and Schlesinger, 1992; Reichstein et al., 2003]. Overall, no significant differences were found between optimized $Q_{10}$ values distribution under relaxed and fix steady state conditions, although most of the optimizations yield $Q_{10}$ values lower in $\operatorname{CCSSA}_{f}(67 \%$ of the cases) (Figure 8a). The lower temperature sensitivity of $\mathrm{Rh}$ in the $\mathrm{CCSSA}_{f}$ cases resulted in reduced seasonal amplitude in $\mathrm{Rh}$ with lower $\mathrm{Rh}$ and thus higher NEP during the warmer growing season yielding a better match to observations. $Q_{10}$ estimates for two sites (FR-Hes and ITNon; Table 5) were $<1$, resulting from the integrated effect of temperature and water availability on $\mathrm{Rh}$. Seasonal climate patterns of temperature and precipitation resulted in positive correlations between water availability and temperature controls. As a consequence, the effects of water availability and temperature were difficult to disentangle, and interfered with parameter retrievals. 

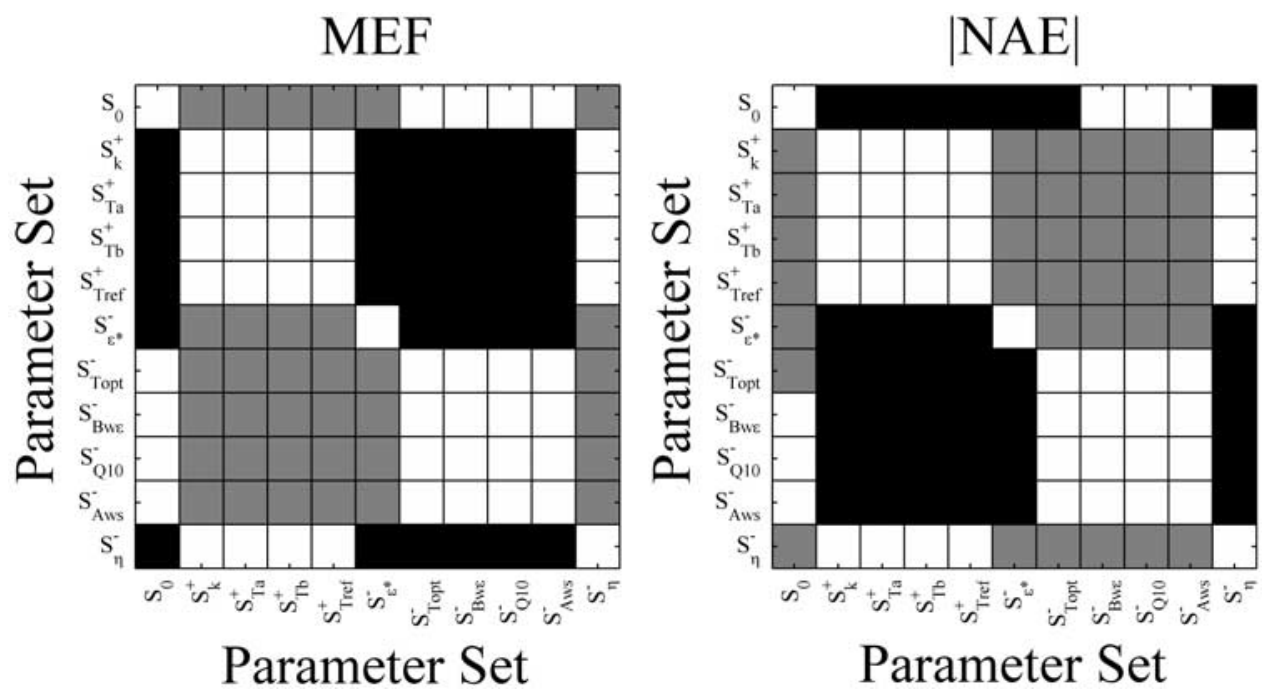

Figure 5. Comparison between model performances of the different parameter sets considered in the optimization exercise: (left) MEF and (right) absolute NAE. Each intersection box indicates differences in model performance measures distribution between the optimized parameter set in the $x$ axis and $y$ axis parameter set. Grey (black) intersection squares indicate model performance distribution for $x$ axis parameter set is significantly lower (higher) than for $y$ axis parameter set.

[36] Generally, for $\mathrm{CCSSA}_{f}$ cases, results illustrate the systematic biases in optimized parameters since the optimization tended to modify the $\mathrm{Rh}$ and NPP responses to climate and phenological drivers, in order to compensate for NEP estimates biases caused by the steady state assumption.

3.4.2. CCSSA Impacts on Parameter Standard Errors

[37] The parameter standard errors (SE) showed significant differences between the different temporal resolutions as a result of varying time series size and smoother variation as time steps became longer. Consequently, the relevance of temporal resolution on parameters standard errors (SE) variability is significant, either as an isolated factor or in interaction with site or parameter set, depending on the parameter (Figure S5). The largest variability in SE was attributed to parameter vector and parameter vector $\mathrm{x}$ site interactions, suggesting constraints on parameters depended mostly on the optimized parameter vector selection.

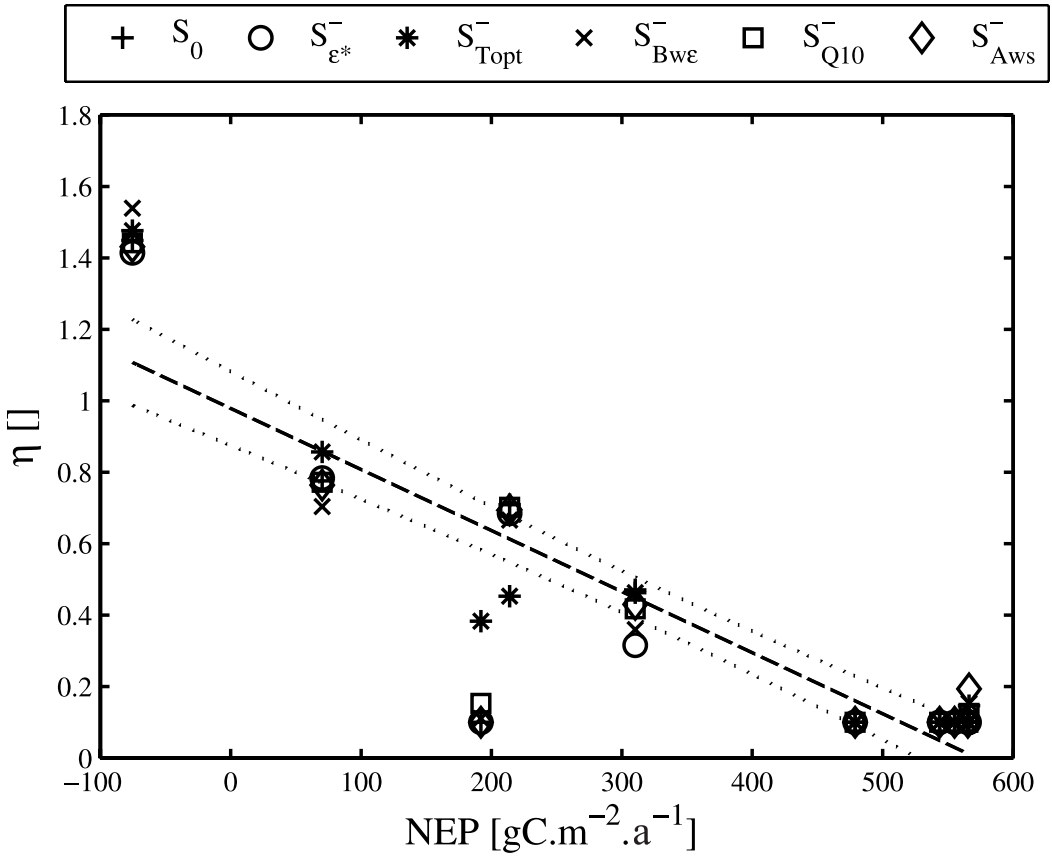

Figure 6. Relationship between mean annual NEP observations and $\eta$ optimization results throughout parameter sets for daily calculations. 

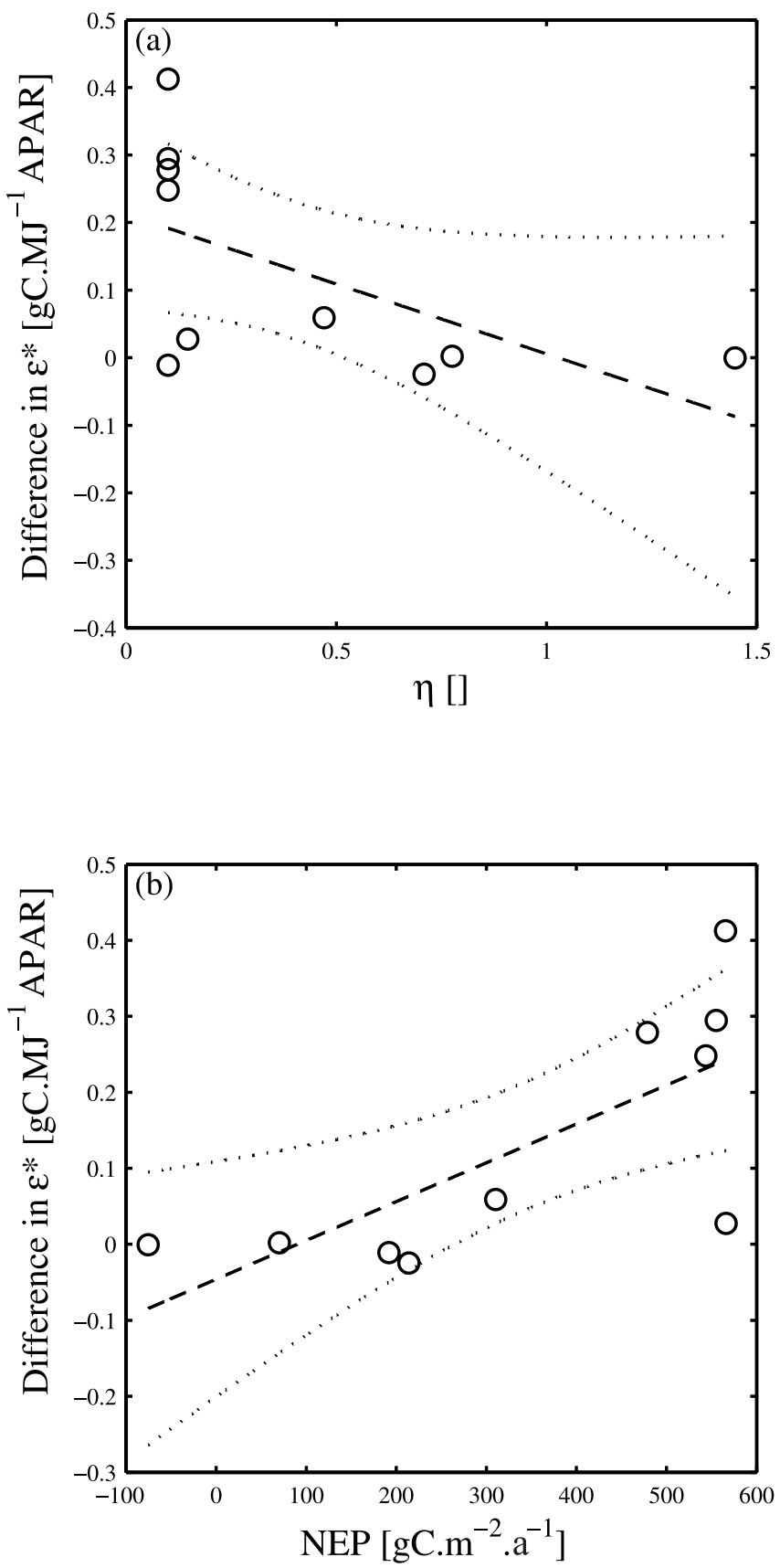

Figure 7. $\operatorname{CCSSA}_{r}$ impact on $\varepsilon^{*}$ estimates reveals: (a) an inverse relationship between differences in $\varepsilon^{*}$ estimates (calculated as the difference between $\varepsilon^{*}\left(S_{0}\right)$ and $\varepsilon^{*}\left(S_{\eta}^{-}\right)$) and $\eta$ estimates, at daily temporal scales, and (b) a direct relationship between differences in $\varepsilon^{*}$ estimates and annual NEP observations, also for daily simulations.

[38] The inclusion of $\eta$ in the optimized parameter set tends to reduce the standard errors (SE) of optimized parameters across temporal scales (Figure 8b). NPP related parameters, $\varepsilon^{*}, T_{\mathrm{opt}}$ and $B_{\text {we }}$ show the highest-median SE reductions $(19,21$, and $38 \%$, respectively) and a significant occurrence of SE improvements throughout sites and temporal resolutions $(61,61$, and $81 \%$, respectively). For $\mathrm{Rh}$ related parameters, $\mathrm{SE}$ was reduced for $\mathrm{A}_{w s}$ in $64 \%$ of the cases, and for $Q_{10}$, in $42 \%$ of the cases. Comparisons between optimized parameter SE for the full parameter set ensembles revealed that SEs are lower in $\mathrm{CCSSA}_{r}$ than in $\mathrm{CCSSA}_{f}$ populations, and that these differences are statistically significant (except for $Q_{10} \mathrm{SE}$ ) (Table 6).

[39] The current results demonstrate that the consideration of a relaxed steady state on inverse model parameter optimization leads to significantly better constrained parameters. Better parameter constraints on different parameters are achieved under $\mathrm{CCSSA}_{r}$, in part because sink or source conditions were not imposed on climate or phenological driven responses in NEP as was the case for $\mathrm{CCSSA}_{f}$ (see section 3.4.1 above).

\subsection{Relaxation of the Carbon Cycle Steady State}

[40] As shown above, the variability in $\eta$ was strongly determined by inter site variability and much less so by temporal resolution or parameter set, corroborating the previous correlation between $\eta$ and magnitude of the source or sink behavior of each site (Figure 6). The $\mathrm{CCSSA}_{r}$ approach forced the adjustments of $\mathrm{C}$ pools after spin up routines, regulating each site's respiration potential hence modifying the differences between mean annual NPP and $\mathrm{Rh}$ fluxes. These results suggest ecosystem respiration $\left(R_{\text {eco }}\right)$ controls on net ecosystem carbon exchange [Valentini et al., 2000]. The parameter $\eta$ and measured $\overline{\mathrm{NEP}} / \overline{R_{\text {eco }}}$ (considered a normalized distance measure from equilibrium) were significantly correlated $(\alpha<0.05)$ for all relaxed steady state parameters sets. Yet, significant positive correlations found between $\overline{\mathrm{NEP}}$ (and also $\overline{\mathrm{NEP}} / \overline{R_{\mathrm{eco}}}$ ) and $\varepsilon^{*}$ in relaxed steady state optimizations suggest stronger sinks are associated with marked NPP seasonality. These results imply a significant role of mean annual gross primary productivity $(\overline{\mathrm{GPP}})$ in determining net ecosystem carbon exchange (Figure S6).

[41] In summary, we find that in the $\mathrm{CCSSA}_{r}$ approach allows for the simulation of $\mathrm{C}$ sinks, by decreasing the soil $\mathrm{C}$ pools, hence the $\mathrm{Rh}$ potential. However, the observed correlations between $\overline{\mathrm{GPP}}$ and $\overline{\mathrm{NEP}}$ (and $\overline{\mathrm{GPP}}$ and $\varepsilon^{*}$ ) suggest that sink magnitudes not only depend on adjustment of $\mathrm{C}$ pools further from an estimated equilibrium per se but also on increasing productivity through adjustment of $\varepsilon^{*}$ in CCSSA $_{r}$. This behavior does not hold true under CCSSA $_{f}$ since higher NPP estimates are counterbalanced by $\mathrm{Rh}$ at steady state.

\subsection{Site History Effects on $\boldsymbol{\eta}$ and Soil C Pools}

[42] The current study relies on $\eta$ to properly quantify the distance from each ecosystem to steady state and, although $\eta$ 's estimate is strongly determined by $\overline{\mathrm{NEP}}$ and the ratio between $\overline{\mathrm{NEP}}$ and $\overline{R_{\text {eco }}}$, we generally found consistent improvements in total soil $\mathrm{C}$ pools measurements between relaxed and fixed steady state assumptions (Figure 9). Five of the sites showed marked improvements, for one site both relaxed and fixed cases were similar to observations and for one site the relaxed and fixed were similar to each other and significantly higher than observations.

[43] In IT-Ro2, FR-LBr, and PT-Mil droughts were observed during measuring period. In this regard, Jarvis et al. [2007] point out the importance of appropriate 
Table 5. Parameter Optimizations Results for $S_{0}$ at Daily Temporal Scale per Site (Parameters Standard Errors in Parentheses)

\begin{tabular}{|c|c|c|c|c|c|}
\hline Site Code & $\varepsilon^{*}$ & $T_{\mathrm{opt}}$ & $B_{w \varepsilon}$ & $Q_{10}$ & $A_{w s}$ \\
\hline ES-ES1 & $0.72(0.02)$ & $17.95(0.53)$ & $0.65(0.02)$ & $3.03(0.23)$ & $0.51(0.02)$ \\
\hline FR-Hes & $0.83(0.02)$ & $15.13(0.27)$ & $0.45(0.06)$ & $0.70(0.04)$ & $0.31(0.05)$ \\
\hline FR-LBr & $0.69(0.03)$ & $7.88(0.43)$ & $0.67(0.03)$ & $1.55(0.11)$ & $0.90(0.04)$ \\
\hline FR-Pue & $0.50(0.02)$ & $5.73(0.30)$ & $0.93(0.04)$ & $1.63(0.12)$ & $0.12(0.01)$ \\
\hline IT-Non & $0.84(0.02)$ & $20.57(0.22)$ & $0.92(0.03)$ & $0.87(0.04)$ & $1.05(0.09)$ \\
\hline IT-PT1 & $1.00(0.02)$ & $21.00(0.38)$ & $0.61(0.02)$ & $1.44(0.09)$ & $0.57(0.04)$ \\
\hline IT-Ren & $0.66(0.01)$ & $10.05(0.38)$ & $1.06(0.10)$ & $1.43(0.09)$ & $5.95(0.35)$ \\
\hline IT-Ro1 & $0.45(0.02)$ & $16.63(0.63)$ & $0.78(0.06)$ & $1.91(0.15)$ & $0.29(0.02)$ \\
\hline IT-Ro2 & $0.82(0.05)$ & $22.85(0.83)$ & $0.82(0.03)$ & $1.94(0.25)$ & $1.18(0.22)$ \\
\hline PT-Mil & $0.39(0.01)$ & $9.75(0.43)$ & $0.73(0.03)$ & $1.18(0.09)$ & $0.92(0.07)$ \\
\hline
\end{tabular}

discrimination of drought related issues in C flux modeling. The nonconsideration of such phenomena may lead to biases in total soil $\mathrm{C}$ balance estimates, as well as in $\mathrm{C}$ partitioning among the soil $\mathrm{C}$ pools, which is of significant importance in regions prone to systematic droughts, as is the case of PT-Mi1 [Pereira et al., 2001, 2007]. Furthermore, in these areas, spin up routines may also yield significant biases in soil $\mathrm{C}$ pools by prescribing transient climate data sets based on averages or smoothed time series, where climate variability and extremes are removed or reduced.

[44] Although the current results demonstrate that relaxed steady state assumptions through $\eta$ approximate modeled from measured total soil $\mathrm{C}$ pools, some important assumptions were made regarding soil $\mathrm{C}$ pools, disturbances and inter annual variability (IAV): (1) although total soil $\mathrm{C}$ pools estimates improved in $\mathrm{CCSSA}_{r}$ optimizations, a correct partitioning between the different soil $\mathrm{C}$ pools is not assumed, due to $\eta$ 's undifferentiated nature; (2) being $\eta$ strongly related to $\overline{\mathrm{NEP}}$, and the $\overline{\mathrm{NEP}} / \overline{R_{\text {eco }}}$ ratio, the relationship between $\eta$ and disturbances is only possible if these cause variations in annual $\mathrm{C}$ balance; and (3) when uniquely analyzing individual years, IAV can be a source of error in the quantification of the distance to steady state.

\subsection{Potential Applications of the $\mathrm{CCSSA}_{r}$ in Biogeochemical Modeling}

[45] The concept of capturing the disequilibrium in carbon fluxes through a parameter $\eta$ has potential implications and applications for generalizing carbon fluxes from site to regional scales. Following the two-component modeling approach by Andrén and Kätterer [1997], first-order soil C dynamics equations can be analytically solved for both pools at steady state (Text S4). Assuming non steady state conditions, $\eta$ can be calculated as:

$$
\eta=1-\frac{1}{h} \frac{\overline{\mathrm{NEP}}}{f \overline{\mathrm{GPP}}}
$$

where $h$ stands for the "humification coefficient", expressing the fraction of annual $\mathrm{C}$ fluxes entering a carbon pool with long turnover times, and $f \overline{\mathrm{GPP}}$ describes the mean annual input of $\mathrm{C}$ to the soil, which in steady state is assumed equivalent to observations of mean annual NPP $(\overline{\mathrm{NPP}})$, considered a constant fraction of $\overline{\mathrm{GPP}}$ [Waring et al., 1998]. Our results show significant correlations $(\alpha<0.002)$ between $\eta$ and $\overline{\mathrm{NEP}} / \overline{\mathrm{GPP}}$ with an offset of $1.026 \pm 0.027$ and a slope of $-3.043 \pm 0.088$, implying an $h$ of $0.7 \pm 0.02$, considering an $f$ of 0.47 [Waring et al., 1998]. Estimates found for $h$ are significantly above values reported by Andrén and Kätterer [1997] (ranging from 0.13 to 0.34), possibly reflecting a carbon sequestration in multiple pools including woody material, while Andrén and Kätterer [1997] considered herbaceous ecosystems [Kätterer et al., $1998]$.

[46] These results suggest an approach to integrate topdown and bottom-up approaches in $\mathrm{C}$ flux modeling, as exemplified by Rayner et al. [2005]. The main goal would be to quantify spatially the distance to steady state conditions in terrestrial ecosystems by constraining the soil $\mathrm{C}$ pools with $\overline{\mathrm{NEP}}$ estimates from atmospheric inversions, and GPP (or NPP) estimates from the ecosystem biogeochemical model. Using equation 5 one could give an estimate of $\eta$ that could be compared to disturbance and land-use history.

\section{Overall Discussion}

[47] The current model evaluation study quantifies the ability of the CASA model to simulate carbon fluxes at the ecosystem scale, and indicates a significant robustness in estimating NEP of ten eddy covariance monitoring sites at different temporal scales. CASA is well suited to evaluate the impact of the steady state approach on model performance and parameterization through one parameter, $\eta$, which relaxes this assumption. The consideration of a relaxed versus a strict steady state approach produces: (1) significant increases in model performance, via increases in MEF and reductions in NAE and (2) improvements in parameter constraints. The correlation between $\eta$ and differences in model performance emphasizes the positive impact of a CCSSA the farther apart an ecosystem is from equilibrium. Overall, a clear distinction can be made between $\mathrm{CCSSA}_{r}$ and $\mathrm{CCSSA}_{f}$ model performance results although a significant intersite variability is observed both in model performance as well as in the results of the parameter optimization. Changes in the optimization results of environmental response parameters associated with significant increases in model performance under CCSSA, suggest parameterization biases under fixed steady state assumption, mainly on NPP related parameters.

[48] The relevance of optimizing $\varepsilon^{*}$ is emphasized in this selection of sites, where GPP is driving $\overline{\mathrm{NEP}}$ observations, and not $\overline{R_{\mathrm{eco}}}$, as commonly found [Reichstein et al., 2007]. The current study demonstrates modeled sink/source magnitudes can be improved by considering both a parameter $\eta$ quantifying the distance to an estimated steady 

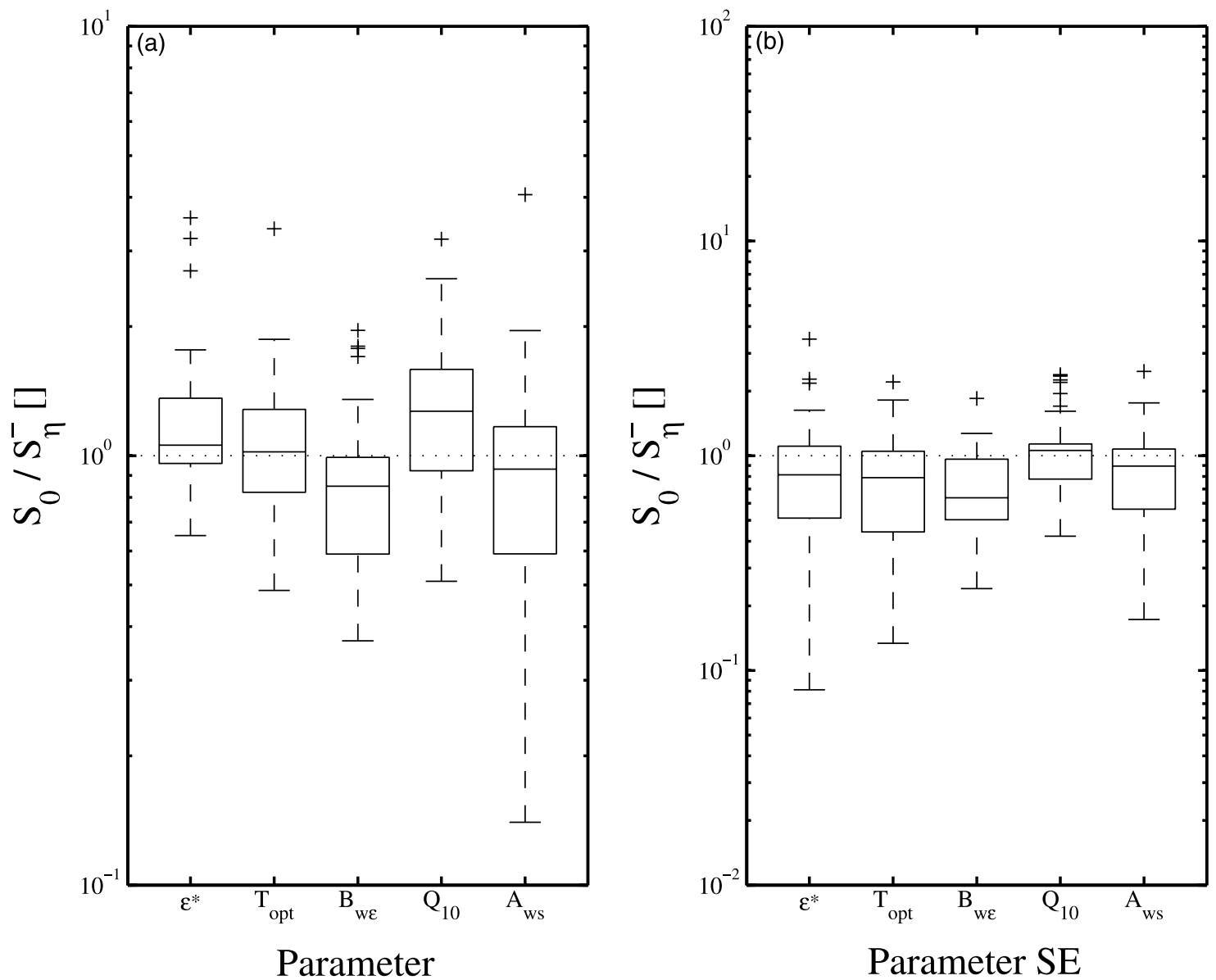

Figure 8. Effects of $\eta$ in optimized parameter constraints. Except for $Q_{10}$, the distribution of the standard error in $S_{0}\left(\mathrm{SE}\left(S_{0}\right)\right)$ generally presents tighter constraints than in $S_{\eta}^{-}\left(\mathrm{SE}\left(S_{\eta}^{-}\right)\right)$. Rectangular boxes are bounded by 25th (lower) and 75th (upper) percentile, while the horizontal line inside indicates the sample median; dashed lines limited by vertical bars indicate the extent of the remaining data, excluding outliers; plus signs indicate statistical outliers.

state situation, yielding adjustments in total $\mathrm{C}$ pools closer to measurements; and adjustments to primary production through $\varepsilon^{*}$. Furthermore, the significance of synchronizing NEP seasonal cycles through $T_{\mathrm{opt}}$ is emphasized by significant improvements in model performance. Potential biases in $\eta$ can occur because of strong NEP interannual variability, suggesting the consideration of time series of multiple years for a robust analysis of $\eta$.

[49] As a limitation we note however, that these calculations hinge on the accuracy of annual sums of eddy covariance flux data, which might even after state-of-the-art corrections underestimate nighttime fluxes and hence overestimate NEP. There are clear indications that errors are site dependent and need further investigation [e.g., Aubinet et al., 2005; Belelli-Marchesini et al., 2007; Marcolla et al., 2005].

[50] From a more generalized modeling perspective the current study demonstrates the usefulness of model-data synthesis approaches for testing conceptual principles used in biogeochemical modeling. In this sense the importance of appropriate and flexible model structures is emphasized, since we showed that inappropriate structure in one part of the model can introduce biased parameter estimates in apparently unrelated other model parts via statistical correlations.

\section{Conclusions}

[51] While previous studies have shown the potential of model inversion against eddy covariance data and have emphasized the importance of data error characterization, our study shows the implications of a typical biogeochem-

Table 6. Results for the Parameters' Standard Errors Mean and Standard Deviation Considering Both a Fixed CCSSA (CCSSA $_{f}$ and a Relaxed CCSSA $\left(\operatorname{CCSSA}_{r}\right)^{\mathrm{a}}$

\begin{tabular}{ccc}
\hline & \multicolumn{2}{c}{ CCSSA } \\
\cline { 2 - 3 } Parameter & CCSSA $_{f}$ & CCSSA $_{r}$ \\
\hline$\varepsilon^{*}$ & $\mathbf{0 . 1 3} \pm \mathbf{0 . 1 5}$ & $\mathbf{0 . 0 8} \pm \mathbf{0 . 0 9}$ \\
$T_{\text {opt }}$ & $\mathbf{2 . 8 5} \pm \mathbf{3 . 4 9}$ & $\mathbf{1 . 3 7} \pm \mathbf{1 . 1 4}$ \\
$B_{w \varepsilon}$ & $\mathbf{0 . 1 6} \pm \mathbf{0 . 1 5}$ & $\mathbf{0 . 1 2} \pm \mathbf{0 . 1 5}$ \\
$Q_{10}$ & $0.46 \pm 0.51$ & $0.42 \pm 0.47$ \\
$A_{w s}$ & $\mathbf{0 . 3 7} \pm \mathbf{0 . 6 8}$ & $\mathbf{0 . 2 3} \pm \mathbf{0 . 8 0}$ \\
\hline
\end{tabular}

${ }^{\mathrm{a}}$ Bold values indicate a statistically significant difference. 


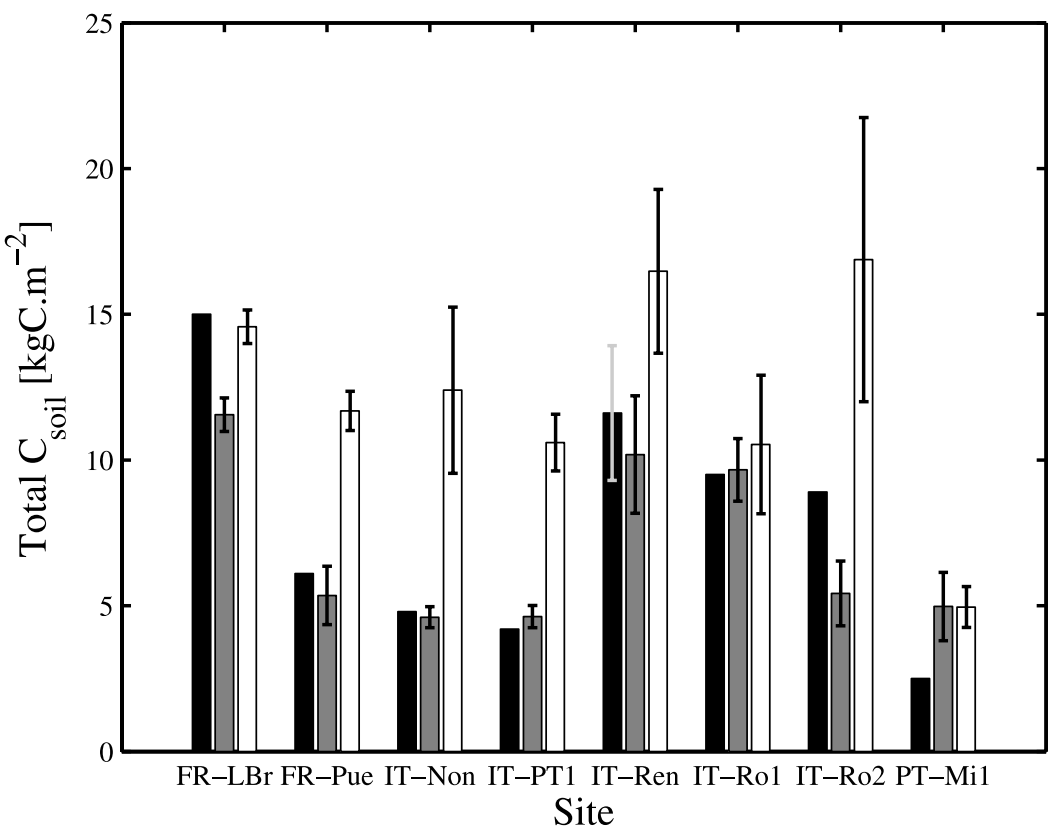

Figure 9. Comparison between total soil $\mathrm{C}$ pools field measurements (black), estimated by the CASA model under relaxed (grey) and fixed (white) steady state conditions, considering different temporal resolutions mean (filled bars) and standard deviation (error bars). Grey error bar represents measurements confidence interval (only present in IT-Ren). Data sources by site: FR-LBr from Loustau et al. [1999]; FR-Pue from Joffre et al. [1996]; IT-Non from F. Miglietta (unpublished data, 2002); IT-PT1 from Ferré et al. [2005]; IT-Ren from Rodeghiero and Cescatti [2005]; IT-Ro1 and IT-Ro2 from Rey et al. [2002]; PT-Mi1 from Pereira et al. [2001].

ical model structure on model performance and parameter retrieval for the first time in a systematic way. Furthermore, our results emphasize the need for future studies on model structure, both in the context of diagnostic as well as prognostic models.

[52] While the overall ability of the CASA model to simulate ecosystem carbon fluxes has been confirmed here, the limitations of the carbon cycle steady state assumption (CCSSA) embodied in almost all biogeochemical modeling approaches has been clearly disclosed. We show that the CCSSA deteriorates not only model performance expressed as model errors or modeling efficiency, but more importantly, leads to biased parameter retrieval in a model-data fusion framework. Indicative of this, the relaxation of the CCSSA via one parameter $\eta$ that relates to imbalance of soil carbon pools yielded better model performance and more constrained parameter estimates. Hence our study clearly demonstrates that implications of model structure for inverse parameter retrieval deserve more attention. In particular the common steady state assumption may compromise model-data synthesis in biogeochemical modeling and needs to be addressed thoroughly. In our study we used a semiempirical correction approach, but future solutions might include a more explicit simulation of reasons for nonsteady state in parameter optimization procedures.

[53] Acknowledgments. We are grateful to Chris Neigh and Martin Jung for helpful comments on the manuscript and for always fruitful discussions. We are also thankful James Randerson, David Hollinger and one anonymous reviewer for constructive comments that very much helped improving the manuscript. This work was funded by the Portuguese Foundation for Science and Technology (FCT) under the CARBERIAN project (contract PDCTE/CTA/49985/2003). N.C. acknowledges the support given by the Portuguese Foundation for Science and Technology (FCT); the European Union under Operational Program "Science and Innovation" (POCI 2010); Ph.D. grant ref. SFRH/BD/6517/2001, cosponsored by the European Social Fund; and the Marie Curie Reintegration grant GLUES (MC MERG-CT-2005-031077) to MR. Research leading to flux data and scientific insight was supported by the CARBOEUROPE-IP project.

\section{References}

Adams, B., A. White, and T. M. Lenton (2004), An analysis of some diverse approaches to modelling terrestrial net primary productivity, Ecol. Modell., 177(3-4), 353-391, doi:10.1016/j.ecolmodel.2004.03.014.

Amthor, J. S., et al. (2001), Boreal forest $\mathrm{CO}_{2}$ exchange and evapotranspiration predicted by nine ecosystem process models: Intermodel comparisons and relationships to field measurements, J. Geophys. Res., 106(D24), 33,623-33,648.

Andrén, O., and T. Kätterer (1997), ICBM: The introductory carbon balance model for exploration of soil carbon balances, Ecol. Appl., 7(4), $1226-1236$

Aubinet, M., et al. (2000), Estimates of the annual net carbon and water exchange of forests: The EUROFLUX methodology, Adv. Ecol. Res., 30, $113-175$.

Aubinet, M., et al. (2005), Comparing $\mathrm{CO}_{2}$ storage and advection conditions at night at different carboeuroflux sites, Boundary Layer Meteorol., 116(1), 63-94.

Baldocchi, D., J. Finnigan, K. Wilson, K. T. Paw U, and E. Falge (2000), On measuring net ecosystem carbon exchange over tall vegetation on complex terrain, Boundary Layer Meteorol., 96(1-2), 257-291.

Barrett, D. J. (2002), Steady state turnover time of carbon in the Australian terrestrial biosphere, Global Biogeochem. Cycles, 16(4), 1108, doi:10.1029/2002GB001860.

Behrenfeld, M. J., et al. (2001), Biospheric primary production during an ENSO transition, Science, 291(5513), 2594-2597. 
Belelli-Marchesini, L., D. Papale, M. Reichstein, N. Vuichard, N. Tchebakova, and R. Valentini (2007), Carbon balance assessment of a natural steppe of southern Siberia by multiple constraint approach, Biogeosciences, 4(4), $581-595$.

Box, E. O. (1988), Estimating the seasonal carbon source-sink geography of a natural, steady-state terrestrial biosphere, J. Appl. Meteorol., 27(10), $1109-1124$

Cannell, M. G. R., and J. H. M. Thornley (2003), Ecosystem productivity is independent of some soil properties at equilibrium, Plant Soil, 257(1), $193-204$

Draper, N., and H. Smith (1981), Applied Regression Analysis, John Wiley, New York.

Dufrêne, E., H. Davi, C. Francois, G. Le Maire, V. Le Dantec, and A. Granier (2005), Modelling carbon and water cycles in a beech forest part I: Model description and uncertainty analysis on modelled NEE, Ecol. Modell., 185(2-4), 407-436, doi:10.1016/j.ecolmodel.2005.01.004.

Epron, D., V. Le Dantec, E. Dufrêne, and A. Granier (2001), Seasonal dynamics of soil carbon dioxide efflux and simulated rhizosphere respiration in a beech forest, Tree Physiol., 21(2-3), 145-152.

Falge, E., et al. (2002), Seasonality of ecosystem respiration and gross primary production as derived from FLUXNET measurements, Agric For. Meteorol., 113(1-4), 53-74

Ferré, C., A. Leip, G. Matteucci, F. Previtali, and G. Seufert (2005), Impact of 40 years poplar cultivation on soil carbon stocks and greenhouse gas fluxes, Biogeosciences Discuss., 2(4), 897-931.

Field, C. B., J. T. Randerson, and C. M. Malmstrom (1995), Global net primary production-Combining ecology and remote-sensing, Remote Sens. Environ., 51(1), 74-88.

Field, C. B., M. J. Behrenfeld, J. T. Randerson, and P. Falkowski (1998), Primary production of the biosphere: Integrating terrestrial and oceanic components, Science, 281(5374), 237-240.

Friedlingstein, P., G. Joel, C. B. Field, and I. Y. Fung (1999), Toward an allocation scheme for global terrestrial carbon models, Global Change Biol., 5(7), 755-770.

Gobron, N., B. Pinty, M. M. Verstraete, and Y. Govaerts (1997), A semidiscrete model for the scattering of light by vegetation, J. Geophys. Res. 102(D8), $9431-9446$.

Hogg, R. V., and J. Ledolter (1987), Engineering Statistics, Macmillan, New York

Janssen, P. H. M., and P. S. C. Heuberger (1995), Calibration of processoriented models, Ecol. Modell., 83(1-2), 55-66.

Jarvis, P., et al. (2007), Drying and wetting of Mediterranean soils stimulates decomposition and carbon dioxide emission: The "Birch effect", Tree Physiol., 27(7), 929-940.

Joffre, R., S. Rambal, and F. Romane (1996), Local variations of ecosystem functions in Mediterranean evergreen oak woodland, Ann. Sci. For. $53(2-3), 561-570$

Kätterer, T., M. Reichstein, O. Andren, and A. Lomander (1998), Temperature dependence of organic matter decomposition: A critical review using literature data analyzed with different models, Biol. Fertil. Soils, 27(3), $258-262$

Kirschbaum, M. U. F. (1995), The temperature dependence of soil organicmatter decomposition, and the effect of global warming on soil organic $\mathrm{C}$ storage, Soil Biol. Biochem., 27(6), 753-760.

Knyazikhin, Y., J. V. Martonchik, R. B. Myneni, D. J. Diner, and S. W. Running (1998), Synergistic algorithm for estimating vegetation canopy leaf area index and fraction of absorbed photosynthetically active radiation from MODIS and MISR data, J. Geophys. Res., 103(D24), 32,25732,275 .

Lasslop, G., M. Reichstein, J. Kattge, and D. Papale (2008), Influences of observation errors in eddy flux data on inverse model parameter estimation, Biogeosciences Discuss., 5, 751-785.

Law, B. E., R. H. Waring, P. M. Anthoni, and J. D. Aber (2000), Measurements of gross and net ecosystem productivity and water vapour exchange of a Pinus ponderosa ecosystem, and an evaluation of two generalized models, Global Change Biol., 6(2), 155-168, doi:10.1046/j.1365-2486.2000.00291.x.

Law, B. E., F. M. Kelliher, D. D. Baldocchi, P. M. Anthoni, J. Irvine, D. Moore, and S. Van Tuyl (2001), Spatial and temporal variation in respiration in a young ponderosa pine forests during a summer drought, Agric. For. Meteorol., 110(1), 27-43.

Loustau, D., P. Berbigier, A. Granier, Y. Brunet, T. Bariac, and R. Valentini (1999), Measuring the carbon balance of European forests: Case studies of the two French sites from the Euroflux Network: Short-term environmental controls on carbon dioxide flux in a boreal coniferous forest: Model computation compared with measurements by eddy, $C$. $R$. Acad. Agric. Fr., 85, 255-264.
Lugo, A. E., and S. Brown (1986), Steady state terrestrial ecosystems and the global carbon cycle, Plant Ecol., 68(2), 83-90.

Marcolla, B., A. Cescatti, L. Montagnani, G. Manca, G. Kerschbaumer, and $\mathrm{S}$. Minerbi (2005), Importance of advection in the atmospheric $\mathrm{CO}_{2}$ exchanges of an alpine forest, Agric. For. Meteorol., 130(3-4), $193-206$.

Masek, J. G., and G. J. Collatz (2006), Estimating forest carbon fluxes in a disturbed southeastern landscape: Integration of remote sensing, forest inventory, and biogeochemical modeling, J. Geophys. Res., 111, G01006, doi:10.1029/2005JG000062

Moffat, A. M., et al. (2007), Comprehensive comparison of gap-filling techniques for eddy covariance net carbon fluxes, Agric. For. Meteorol., 147(3-4), 209-232.

Monteith, J. L. (1972), Solar-radiation and productivity in tropical ecosystems, J. Appl. Ecol., 9(3), 747-766.

Monteith, J. L. (1977), Climate and efficiency of crop production in Britain, Philos. Trans. R. Soc. London Ser. B, 281(980), 277-294.

Morales, P., et al. (2005), Comparing and evaluating process-based ecosystem model predictions of carbon and water fluxes in major European forest biomes, Global Change Biol., 11(12), 2211-2233, doi:10.1111/ j.1365-2486.2005.01036.x.

Myneni, R. B., S. Maggion, J. Iaquinto, J. L. Privette, N. Gobron, B. Pinty, D. S. Kimes, M. M. Verstraete, and D. L. Williams (1995), Optical remote-sensing of vegetation-Modeling, caveats, and algorithms, Remote Sens. Environ., 51(1), 169-188.

Myneni, R. B., et al. (2002), Global products of vegetation leaf area and fraction absorbed PAR from year one of MODIS data, Remote Sens. Environ., 83(1-2), 214-231.

Nash, J. E., and J. V. Sutcliffe (1970), River flow forecasting through conceptual models: part I: A discussion of principles, J. Hydrol., 10(3), $282-290$.

Oak Ridge National Laboratory Distributed Active Archive Center (2006a), FLUXNET Integrating Worldwide $\mathrm{CO}_{2}$ Flux Measurements, http:// www.fluxnet.ornl.gov/fluxnet/index.cfm, Oak Ridge Natl. Lab. Distrib. Active Arch. Cent., Oak Ridge, Tenn., Jan. 2006.

Oak Ridge National Laboratory Distributed Active Archive Center (2006b), MODIS Subsetted Land Products, Collection 4, http://www.daac.ornl. gov/MODIS/modis.html, Oak Ridge Natl. Lab. Distrib. Active Arch. Cent., Oak Ridge, Tenn., Jan. 2006.

Papale, D., and A. Valentini (2003), A new assessment of European forests carbon exchanges by eddy fluxes and artificial neural network spatialization, Global Change Biol., 9(4), 525-535.

Papale, D., et al. (2006), Towards a standardized processing of Net Ecosystem Exchange measured with eddy covariance technique: Algorithms and uncertainty estimation, Biogeosciences, 3, 571-583.

Parton, W. J., D. S. Schimel, C. V. Cole, and D. S. Ojima (1987), Analysis of factors controlling soil organic-matter levels in Great Plains Grasslands, Soil Sci. Soc. Am. J., 51(5), 1173-1179.

Pereira, J. S., M. Chaves, J. S. David, T. S. David, M. Rayment, M. Vaz, and J. Banza (2001), The importance of drought in the control of water and carbon fluxes in an evergreen oak woodland in southwest Iberian Peninsula, paper presented at 86th Annual Meeting, Ecological Society of America, Madison, Wis., Aug. 2001

Pereira, J. S., et al. (2007), Net ecosystem carbon exchange in three contrasting Mediterranean ecosystems - The effect of drought, Biogeosciences, 4(5), 791-802.

Pietsch, S. A., and H. Hasenauer (2006), Evaluating the self-initialization procedure for large-scale ecosystem models, Global Change Biol., 12(9), 1658-1669, doi:10.1111/j.1365-2486.2006.01211.x

Potter, C. S., J. T. Randerson, C. B. Field, P. A. Matson, P. M. Vitousek, H. A. Mooney, and S. A. Klooster (1993), Terrestrial Ecosystem Production: a Process Model Based on Global Satellite and Surface Data, Global Biogeochem. Cycles, 7(4), 811-841.

Potter, C. S., E. A. Davidson, S. A. Klooster, D. C. Nepstad, G. H. De Negreiros, and V. Brooks (1998), Regional application of an ecosystem production model for studies of biogeochemistry in Brazilian Amazonia, Global Change Biol., 4(3), 315-333.

Potter, C. S., S. E. Alexander, J. C. Coughlan, and S. A. Klooster (2001), Modeling biogenic emissions of isoprene: Exploration of model drivers, climate control algorithms, and use of global satellite observations, Atmos. Environ., 35(35), 6151-6165.

Quinton, J. N. (1997), Reducing predictive uncertainty in model simulations: A comparison of two methods using the European Soil Erosion Model (EUROSEM), Catena, 30(2-3), 101-117.

Raich, J. W., and W. H. Schlesinger (1992), The global carbon-dioxide flux in soil respiration and its relationship to vegetation and climate, Tellus Ser. $B, 44(2), 81-99$. 
Randerson, J. T., M. V. Thompson, C. M. Malmstrom, C. B. Field, and I. Y. Fung (1996), Substrate Limitations for Heterotrophs: Implications for Models That Estimate the Seasonal Cycle of Atmospheric $\mathrm{CO}_{2}$, Global Biogeochem. Cycles, 10(4), 585-602.

Randerson, J. T., et al. (2002), Carbon isotope discrimination of arctic and boreal biomes inferred from remote atmospheric measurements and a biosphere-atmosphere model, Global Biogeochem. Cycles, 16(3), 1028, doi:10.1029/2001GB001435.

Randerson, J. T., G. R. van der Werf, G. J. Collatz, L. Giglio, C. J. Still, P. Kasibhatla, J. B. Miller, J. W. C. White, R. S. DeFries, and E. S. Kasischke (2005), Fire emissions from $\mathrm{C}_{3}$ and $\mathrm{C}_{4}$ vegetation and their influence on interannual variability of atmospheric $\mathrm{CO}_{2}$ and $\delta^{13} \mathrm{CO}_{2}$, Global Biogeochem. Cycles, 19, GB2019, doi:10.1029/2004GB002366.

Rannik, U., P. Kolari, T. Vesala, and P. Hari (2006), Uncertainties in measurement and modelling of net ecosystem exchange of a forest, Agric. For Meteorol., 138(1-4), 244-257, doi:10.1016/j.agrformet.2006.05.007.

Rayner, P. J., M. Scholze, W. Knorr, T. Kaminski, R. Giering, and H. Widmann (2005), Two decades of terrestrial carbon fluxes from a carbon cycle data assimilation system (CCDAS), Global Biogeochem. Cycles, 19, GB2026, doi:10.1029/2004GB002254.

Reichstein, M., J. Tenhunen, O. Roupsard, J.-M. Ourcival, S. Rambal, F. Miglietta, A. Peressotti, M. Pecchiari, G. Tirone, and R. Valentini (2003), Inverse modeling of seasonal drought effects on canopy $\mathrm{CO}_{2}$ $\mathrm{H}_{2} \mathrm{O}$ exchange in three Mediterranean ecosystems, J. Geophys. Res., 108(D23), 4726, doi:10.1029/2003JD003430.

Reichstein, M., et al. (2005), On the separation of net ecosystem exchange into assimilation and ecosystem respiration: Review and improved algorithm, Global Change Biol., 11(9), 1424-1439.

Reichstein, M., et al. (2007), Determinants of terrestrial ecosystem carbon balance inferred from European eddy covariance flux sites, Geophys. Res. Lett., 34, L01402, doi:10.1029/2006GL027880.

Rey, A., E. Pegoraro, V. Tedeschi, I. De Parri, P. G. Jarvis, and R. Valentin (2002), Annual variation in soil respiration and its components in a coppice oak forest in central Italy, Global Change Biol., 8(9), 851-866.

Richardson, A. D., et al. (2006a), Comparing simple respiration models for eddy flux and dynamic chamber data, Agric. For. Meteorol., 141(2-4), $219-234$

Richardson, A. D., et al. (2006b), A multi-site analysis of random error in tower-based measurements of carbon and energy fluxes, Agric. For. Meteorol., 136(1-2), 1-18, doi:10.1016/j.agrformet.2006.01.007.

Richardson, A. D., et al. (2008), Statistical properties of random $\mathrm{CO}_{2}$ flux measurement uncertainty inferred from model residuals, Agric. For Meteorol., 148, 38-50.

Rodeghiero, M., and A. Cescatti (2005), Main determinants of forest soil respiration along an elevation/temperature gradient in the Italian Alps, Global Change Biol., 11(7), 1024-1041.

Ruimy, A., B. Saugier, and G. Dedieu (1994), Methodology for the estimation of terrestrial net primary production from remotely sensed data, J. Geophys. Res., 99(D3), 5263-5283.

Ruimy, A., et al. (1999), Comparing global models of terrestrial net primary productivity (NPP): Analysis of differences in light absorption and lightuse efficiency, Global Change Biol., 5, 56-64.

Schimel, D. S., B. H. Braswell, and W. J. Parton (1997), Equilibration of the terrestrial water, nitrogen, and carbon cycles, Proc. Natl. Acad. Sci. U. S. A., 94(16), 8280-8283.

Sellers, P. J., S. O. Los, C. J. Tucker, C. O. Justice, D. A. Dazlich, G. J. Collatz, and D. A. Randall (1996), A revised land surface parameterization (SiB2) for atmospheric GCMs: 2. The generation of global fields of terrestrial biophysical parameters from satellite data, J Clim., 9(4), $706-737$
Smith, J. U., P. Smith, and T. M. Addiscott (1996), Quantitative methods to evaluate and compare soil organic matter (SOM) models, in Evaluation of Soil Organic Matter Models: Using Existing Long-Term Datasets, edited by D. S. Powlson et al., pp. 181-199, Springer-Verlag, New York.

Tenhunen, J. D., R. Valentini, B. Kostner, R. Zimmermann, and A. Granier (1998), Variation in forest gas exchange at landscape to continental scales, Ann. Sci. For, 55(1-2), 1-11.

Trudinger, C. M., et al. (2007), OptIC project: An intercomparison of optimization techniques for parameter estimation in terrestrial biogeochemical models, J. Geophys. Res., 112, G02027, doi:10.1029/ 2006JG000367.

Valentini, R, et al. (2000), Respiration as the main determinant of carbon balance in European forests, Nature, 404(6780), 861-865.

van der Werf, G. R., J. T. Randerson, G. J. Collatz, and L. Giglio (2003), Carbon emissions from fires in tropical and subtropical ecosystems, Global Change Biol., 9(4), 547-562.

Viovy, N., O. Arino, and A. S. Belward (1992), The best index slope extraction (BISE): A method for reducing noise in NDVI time-series, Int. J. Remote Sens., 13(8), 1585-1590.

Wang, Y. P., D. Baldocchi, R. A. Y. Leuning, E. V. A. Falge, and T. Vesala (2006), Estimating parameters in a land-surface model by applying nonlinear inversion to eddy covariance flux measurements from eight FLUXNET sites, Global Change Biol., 12, 1-12, doi:10.1111/j.13652486.2006.01225.X.

Waring, R. H., J. J. Landsberg, and M. Williams (1998), Net primary production of forests: A constant fraction of gross primary production? Tree Physiol., 18(2), 129-134.

Wutzler, T., and M. Reichstein (2007), Soils apart from equilibriumConsequences for soil carbon balance modelling, Biogeosciences, 4(1), $125-136$

Xu, T., L. White, D. Hui, and Y. Luo (2006), Probabilistic inversion of a terrestrial ecosystem model: Analysis of uncertainty in parameter estimation and model prediction, Global Biogeochem. Cycles, 20, GB2007, doi:10.1029/2005GB002468.

P. Berbigier, UR1263 Ecologie Fonctionnelle et Physique de L'environnement, Institut National de la Recherche Agronomique, 69 Route d'Arcachon, F-33612, Bordeaux, France.

A. Carrara and M. J. Sanz, Fundacion Centro de Estudios Ambientales del Mediterráneo, Parque Tecnológico, C/ Charles R. Darwin 14, E-46980 Valencia, Spain.

N. Carvalhais and J. Seixas, Faculdade de Ciências e Tecnologia, Universidade Nova de Lisboa, P-2829-516 Caparica, Portugal. (ncarvalhais@ fct.unl.pt;nmmc@fct.unl.pt)

G. J. Collatz, NASA Goddard Space Flight Center, Mail Code 130, Greenbelt, MD 20771, USA.

A. Granier, Ecologie et Ecophysiologie Forestières, Institut National de la Recherche Agronomique, Centre de Nancy, F-54280 Champenoux, France.

L. Montagnani, Servizi Forestali, Agenzia per l'Ambiente, Provincia Autonoma di Bolzano, Via Brennero 6, I-39100 Bolzano, Italy.

D. Papale and R. Valentini, Department of Forest Environment and Resources, University of Tuscia, Viterbo I-01100, Italy.

J. S. Pereira, Instituto Superior de Agronomia, Tapada da Ajuda, P-1349017 Lisboa, Portugal

S. Rambal, DREAM Unit, Centre d'Ecologie Fonctionelle et Evolutive, UMR 5175, CNRS, 1919 Route de Mende, F-34293 Montpellier, France.

M. Reichstein, Max-Planck-Institut für Biogeochemie, P.O. Box 1001 64, D-07701 Jena, Germany. 